\title{
Age-dependency of terminal ileum tissue resident memory $T$ cell responsiveness profiles to S. Typhi following oral Ty21a immunization in humans
}

\author{
Jayaum S. Booth ${ }^{1,2^{*}}$, Eric Goldberg ${ }^{3,4}$, Seema A. Patil ${ }^{3,4}$, Robin S. Barnes ${ }^{1}$, Bruce D. Greenwald ${ }^{3,4}$ and
} Marcelo B. Sztein ${ }^{1,2,3,5^{*}}$

\begin{abstract}
Background: The impact of aging on the immune system is unequivocal and results in an altered immune status termed immunosenescence. In humans, the mechanisms of immunosenescence have been examined almost exclusively in blood. However, most immune cells are present in tissue compartments and exhibit differential cell (e.g., memory T cells $-T_{M}$ ) subset distributions. Thus, it is crucial to understand immunosenescence in tissues, especially those that are exposed to pathogens (e.g., intestine). Using a human model of oral live attenuated typhoid vaccine, Ty21a, we investigated the effect of aging on terminal ileum (TI) tissue resident memory $T\left(T_{R M}\right)$ cells. $T_{\text {RM }}$ provide immediate adaptive effector immune responsiveness at the infection site. However, it is unknown whether aging impacts $T_{\text {RM }}$ S. Typhi-responsive cells at the site of infection (e.g., TI). Here, we determined the effect of aging on the induction of TI S. Typhi-responsive $T_{\text {RM }}$ subsets elicited by Ty21a immunization.
\end{abstract}

Results: We observed that aging impacts the frequencies of TI-lamina propria mononuclear cells (LPMC) $T_{M}$ and $T_{R M}$ in both Ty21a-vaccinated and control groups. In unvaccinated volunteers, the frequencies of LPMC CD103CD4+ $T_{R M}$ displayed a positive correlation with age whilst the CD4/CD8 ratio in LPMC displayed a negative correlation with age. We observed that elderly volunteers have weaker $S$. Typhi-specific mucosal immune responses following Ty21a immunization compared to adults. For example, CD103+ CD4+ $T_{\text {RM }}$ showed reduced IL-17A production, while CD103- CD4+ $T_{\text {RM }}$ exhibited lower levels of IL-17A and IL-2 in the elderly than in adults following Ty21a immunization. Similar results were observed in LPMC CD8+ $T_{R M}$ and CD103- CD8+ T cell subsets. A comparison of multifunctional (MF) profiles of both CD4+ and CD8+ $T_{R M}$ subsets between elderly and adults also showed significant differences in the quality and quantity of elicited single $(S)$ and MF responses.

Conclusions: Aging influences tissue resident $T_{M} S$. Typhi-specific responses in the terminal ileum following oral Ty21a-immunization. This study is the first to provide insights in the generation of local vaccine-specific responses in the elderly population and highlights the importance of evaluating tissue immune responses in the context of infection and aging.

(Continued on next page)

\footnotetext{
* Correspondence: jbooth@som.umaryland.edu; msztein@som.umaryland.edu ${ }^{1}$ Center for Vaccine Development and Global Health, University of Maryland School of Medicine, Baltimore, MD 21201, USA

Full list of author information is available at the end of the article
}

(C) The Author(s). 2021 Open Access This article is licensed under a Creative Commons Attribution 4.0 International License, which permits use, sharing, adaptation, distribution and reproduction in any medium or format, as long as you give appropriate credit to the original author(s) and the source, provide a link to the Creative Commons licence, and indicate if changes were made. The images or other third party material in this article are included in the article's Creative Commons licence, unless indicated otherwise in a credit line to the material. If material is not included in the article's Creative Commons licence and your intended use is not permitted by statutory regulation or exceeds the permitted use, you will need to obtain permission directly from the copyright holder. To view a copy of this licence, visit http://creativecommons.org/licenses/by/4.0/. The Creative Commons Public Domain Dedication waiver (http://creativecommons.org/publicdomain/zero/1.0/) applies to the data made available in this article, unless otherwise stated in a credit line to the data. 
(Continued from previous page)

Trial registration: This study was approved by the Institutional Review Board and registered on ClinicalTrials.gov (identifier NCT03970304, Registered 29 May 2019 - Retrospectively registered).

Keywords: Aging, Vaccine-induced responses, Tissue resident memory T cells, Terminal ileum LPMC, Ty21a, Oral vaccine

\section{Background}

Aging is associated with the waning of the immune system which progressively declines in function resulting in the diminution of humoral and cellular immune responses [1, 2], a process termed immunosenescence. Studies have shown that negative clinical outcomes in populations of older adults correlate with immunosenescence $[3,4]$. For example, viral and bacterial infections (e.g., influenza, herpes zoster and pneumococcal diseases) are more severe in older adults than in younger adults [57]. While vaccines are among the most cost-effective interventions in public health against infectious diseases, vaccine-induced responses in the elderly are usually of lower magnitude and do not confer long-term protective immunity in this population [8-11]. Alterations in the $\mathrm{T}$ cell repertoire also have been characterized in aging $[12,13]$. However, our current understanding of human immunosenescence is primarily derived from studies using peripheral blood while age-associated changes in the mucosal microenvironment are extremely limited. This represents a crucial knowledge gap as mucosal infections (e.g., respiratory, gastrointestinal and urinary tracts) are major causes of morbidity and mortality in the elderly. Furthermore, it is important to understand immunity to pathogens at the infection sites (mostly tissues) in the context of aging.

The induction of antigen-specific $\mathrm{T}$ cell and $\mathrm{B}$ cell responses are crucial for protective immunity against pathogens. In the elderly, both the quantity and quality of antibody responses are inferior to those observed among younger individuals [14]. Importantly, aging affects the $\mathrm{T}$ cell compartment as shown by the contraction of the naïve $\mathrm{T}$ cell repertoire [15] and expansion of terminally differentiated cell subsets with altered effector functions [16]. Recently, a new memory $T$ cell subset abundant in peripheral tissues, tissue resident memory $\mathrm{T}$ cells $\left(T_{R M}\right)$ have been shown to be central for eliciting and mediating protective immunity at the site of infection $[17,18] . T_{R M}$ represent a non-migratory population of $T_{M}$ that is phenotypically different from circulating $\mathrm{T}_{\mathrm{M}}$ subsets (e.g., $\mathrm{T}$ central memory $\left(\mathrm{T}_{\mathrm{CM}}\right)$ and $\mathrm{T}$ effector memory $\left(\mathrm{T}_{\mathrm{EM}}\right)$ ) and mediate rapid effector immune responses following antigen recall [18]. Human $\mathrm{T}_{\mathrm{RM}}$ are mainly characterized phenotypically by high expression of CD69, a key marker for distinguishing between circulating and resident $T_{M}$ [19]. Integrin $\alpha E \beta 7$ (CD103), the ligand to E-cadherin, is also used to characterize $T_{R M}$ but CD103 expression is mostly confined to CD8+ $T_{R M}$ and a minor subset of $C D 4+T_{R M}[19-22]$. In the human intestine, the majority of $\mathrm{CD} 4+\mathrm{T}_{\mathrm{RM}}$ are $\mathrm{CD} 103-\mathrm{CD} 69+$ and a minority are CD103+ CD69+ [19] while CD8+ $\mathrm{T}_{\mathrm{RM}}$ are mostly CD103+ CD69+. Very little information is available concerning the presence and role of either $\mathrm{CD} 4+$ and $\mathrm{CD} 8+\mathrm{T}_{\mathrm{RM}}$ populations during immunosenescence. It is also unclear whether these local $T_{R M}$ cells are affected by the aging process in terms of quantity (frequencies of cell subsets) and, importantly, in the characteristics of their responses to pathogens at the site of infection following infection or oral immunization. Furthermore, we have a very limited understanding of the mechanisms of immunosenescence in the local intestinal mucosa.

Most human pathogens infect the host through mucosal sites; however, few licensed oral vaccines (e.g., Salmonella enterica serovar Typhi (S. Typhi)) are available. Currently, there are two licensed typhoid vaccines in the USA, namely Ty21a, a live attenuated oral vaccine and the parenteral Vi polysaccharide vaccine [23, 24]. Ty21a can invade the mucosa and replicate for only a few cycles, mimicking natural infection. Ty21a confers a moderate level of long-lived protection $(60-80 \%, 5-7$ years) in the field [24]. However, the mechanisms by which $S$. Typhi or Ty21a induce $T_{R M}$ responses in the TI has not yet been fully explored in adults [25-30] and no information is available in the elderly. Although the human gastrointestinal tract constitutes a major reservoir of total body lymphocytes $(\sim 60 \%)$ and represents an area of high antigenic exposure, our understanding of the mechanisms of protection from infection and oral vaccination in the gut mucosa is very limited, particularly with respect to the immunologic events that follow the administration of oral vaccines. This wide gap in knowledge is impeding the rational development of new oral vaccines for pathogens that gain access to the host through the gastrointestinal tract, especially for the elderly.

In this study, we analyzed age-related changes of TI LPMC memory $\mathrm{T}$ cells obtained from Ty21a-vaccinated and unvaccinated individuals by comparing: (i) TI LPMC CD4+ and CD8 $+T_{M} / T_{R M}$ cell subsets frequencies, and (ii) TI LPMC CD4+ and CD8+ $\mathrm{T}_{\mathrm{M}} / \mathrm{T}_{\mathrm{RM}} S$. Typhispecific responses following Ty21a immunization. These comparisons provide unique insights into the generation of age-associated $S$. Typhi specific responses in the human TI mucosa. 


\section{Results}

Aging influences the frequencies of TI LPMC $T_{M}$ and $T_{R M}$ cells subsets

Recent evidence suggests that aging influences the frequencies and absolute numbers of $\mathrm{T}$ cells in peripheral blood. However, the effect of aging on $\mathrm{T}$ cells frequencies in the human intestine particularly in the terminal ileum (TI) is unknown. To explore this phenomenon, we characterized freshly isolated TI-LPMC CD4+ and CD8+ T cells including their memory subset distribution, as well as tissue resident subsets in specimens obtained from biopsies of Ty21a-vaccinated and unvaccinated volunteers using the gating strategy depicted in Fig. S1A. No differences in total LPMC $\mathrm{T}$ cell frequencies as measured by CD3 expression were detected between elderly ( $\geq 60 \mathrm{yrs}$.) and adults (< 60 yrs.) regardless of Ty21a immunization (Fig. $\mathrm{S} 1 \mathrm{~B})$. Interestingly, CD3+ CD4+ T cell frequencies were observed to decrease significantly $(p<0.05)$ in elderly as compared to adult unvaccinated volunteers. However following Ty21a, no differences were observed in the frequencies of CD4+ $\mathrm{T}$ cells (Fig. S1B). Regarding CD3+ CD8+ T cells, we observed a trend $(p=0.08)$ to be present at higher levels in the elderly than in adult unvaccinated volunteers (Fig. S1B). Similar to CD4+ T cells, no differences were observed in the frequencies of CD8+ T cells following Ty21a immunization (Fig. S1B).

Subsequently, we determined the frequencies of LPMC memory $\mathrm{T}\left(\mathrm{T}_{\mathrm{M}}\right)$ subsets namely $\mathrm{T}$-central/memory $\left(\mathrm{T}_{\mathrm{CM}}\right)$ (CD62L+ CD45RA-), T-effector/memory ( $\left.\mathrm{T}_{\mathrm{EM}}\right)$ (CD62LCD45RA-), $\mathrm{T}_{\mathrm{EM}^{-}} \mathrm{CD} 45 \mathrm{RA}+\left(\mathrm{T}_{\mathrm{EMRA}}\right)(\mathrm{CD} 62 \mathrm{~L}-\mathrm{CD} 45 \mathrm{RA}+)$ and $\mathrm{T}$ naïve ( $\left.\mathrm{T}_{\text {Naïve }}\right)(\mathrm{CD} 62 \mathrm{~L}+\mathrm{CD} 45 \mathrm{RA}+)$ using $\mathrm{CD} 45 \mathrm{RA}$ and CD62L markers to define these subsets in elderly and adult volunteers. We observed that in unvaccinated volunteers, LPMC CD4 $+\mathrm{T}_{\mathrm{CM}}$ (trend; $p=0.07$ ) and $\mathrm{T}_{\text {Naive }}$ (significant; $p<0.05$ ) subsets exhibited lower frequencies in the elderly as compared to adults (Fig. 1a). However, no

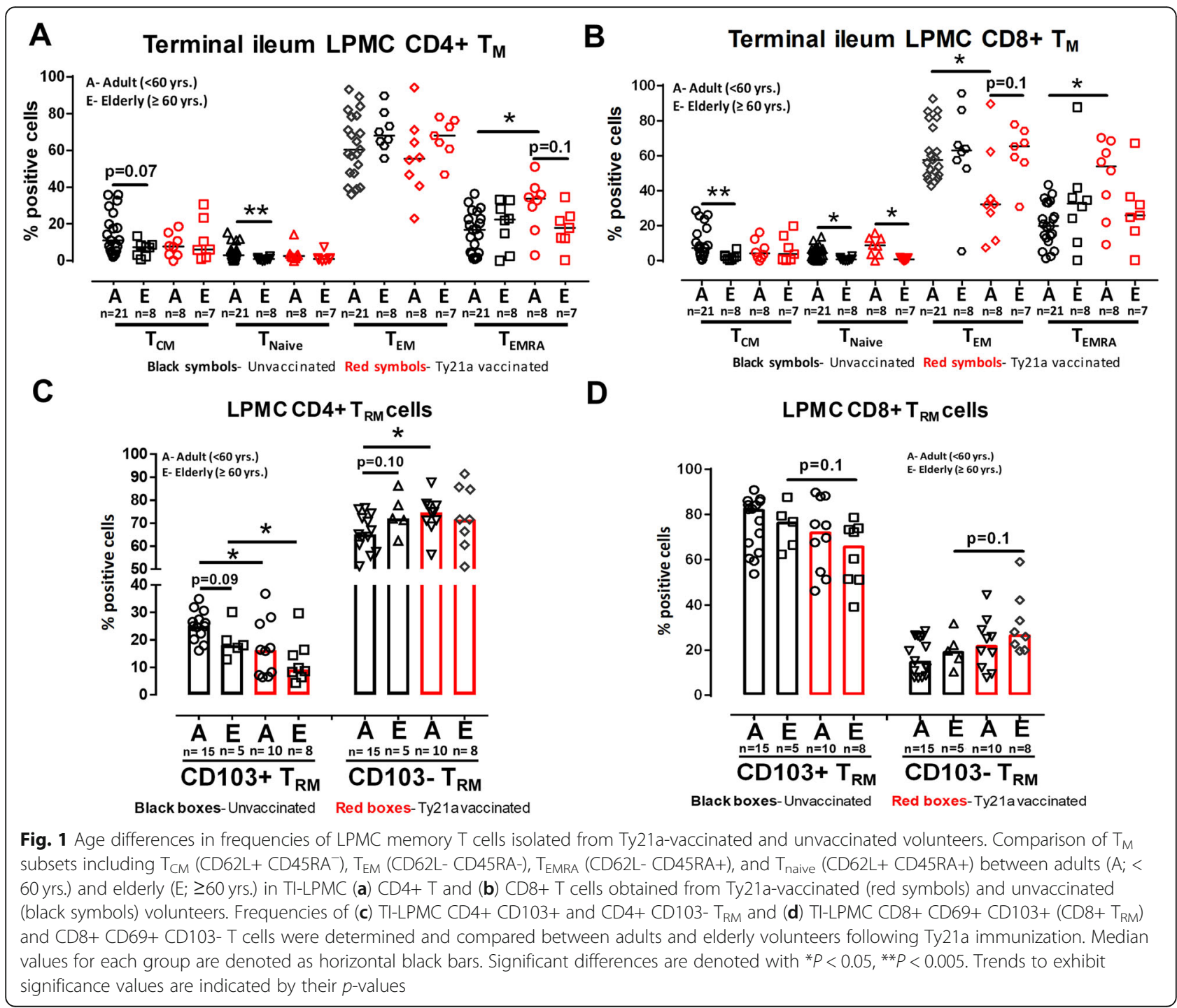


statistically significant differences were observed between LPMC CD4+ $\mathrm{T}_{\mathrm{EM}}$ and $\mathrm{T}_{\mathrm{EMRA}}$ in unvaccinated volunteers (Fig. 1a). Following Ty21a immunization, no statistically significant differences were observed in LPMC CD4+ $\mathrm{T}_{M}$ subsets except for a trend $(p=0.1)$ to show decreases in the frequencies of CD4+ $T_{\text {EMRA }}$ (Fig. 1a). Similar observations for $\mathrm{CD} 8+\mathrm{T}_{M}$ subsets in unvaccinated volunteers were noted with LPMC CD8+ $\mathrm{T}_{\mathrm{CM}}$ and $\mathrm{T}_{\text {Naive }}$ frequencies which were significantly $(p<0.05)$ lower in the elderly (Fig. 1b). However, following Ty21a immunization, no statistically significant differences were observed within LPMC CD4+ $\mathrm{T}_{\mathrm{CM}}$ and $\mathrm{T}_{\mathrm{EMRA}}$ subsets between the two groups (Fig. 1a). Interestingly, following Ty21a immunization, LPMC CD8 $+\mathrm{T}_{\text {Naive }}$ showed statistically significant $(p<0.05)$ lower levels in the elderly as compared to adult volunteers while CD8+ $\mathrm{T}_{\mathrm{EM}}$ showed a trend $(p=0.1)$ to exhibit increases in the elderly compared to adult volunteers following Ty21a immunization (Fig. 1b).

We next focused on the newly defined tissue resident memory T cells using CD69 and CD103 markers to delineate both $\mathrm{CD} 4+$ and $\mathrm{CD} 8+\mathrm{T}_{\mathrm{RM}}$ subsets. Interestingly, in unvaccinated volunteers, we noted that there was a trend $(p=0.09)$ for lower frequencies of CD103+ CD4+ $\mathrm{T}_{\mathrm{RM}}$ in the elderly as compared to adults while the frequencies of CD103- CD4+ $\mathrm{T}_{\mathrm{RM}}$ showed a trend $(p=0.1)$ to be higher in the elderly as compared to adults (Fig. 1c). Following Ty21a immunization, no statistically significant differences were observed in the frequencies of CD103+ and $\mathrm{CD} 103-\mathrm{CD} 4+\mathrm{T}_{\mathrm{RM}}$ between adults and the elderly. The frequencies of both LPMC CD8+ $\mathrm{T}_{\mathrm{RM}}$ and CD103$\mathrm{CD} 8+\mathrm{T}$ cells were not significantly different between elderly and adult volunteers regardless of Ty21a vaccination (Fig. 1d). Of note, following Ty21a immunization, we observed significant $(p<0.05)$ decreases in the frequencies of $\mathrm{CD} 103+\mathrm{CD} 4+\mathrm{T}_{\mathrm{RM}}$ in both adults and the elderly and a significant $(p<0.05)$ increase in the frequency of CD103$\mathrm{CD} 4+\mathrm{T}_{\mathrm{RM}}$ in adults but not in the elderly (Fig. 1c). A similar trend $(p=0.1)$ to show increases in the elderly was observed in CD103- CD8+ $\mathrm{T}_{\mathrm{RM}}$ (Fig. 1d).

\section{Age-association of LPMC CD4+ and CD8+ tissue resident cells}

Tissue resident memory cells plays an important role in protective immunity against pathogens. However, it is unknown whether terminal ileum $\mathrm{T}_{\mathrm{RM}}$ frequencies are correlated with age in unvaccinated and Ty21a-vaccinated individuals. Here we used Pearson's correlation analysis to determine the degree of association between age and $T_{R M}$ frequencies in Ty21a-vaccinated and unvaccinated individuals. Interestingly, in unvaccinated volunteers, we observed that LPMC CD103- CD4+ $\mathrm{T}_{\mathrm{RM}}$ displayed a significant $(p<0.05)$ positive correlation with age of volunteers while CD103+CD4+ $\mathrm{T}_{\mathrm{RM}}$ displayed a trend $(p=0.06)$ towards a negative correlation with increasing age (Fig. 2a).

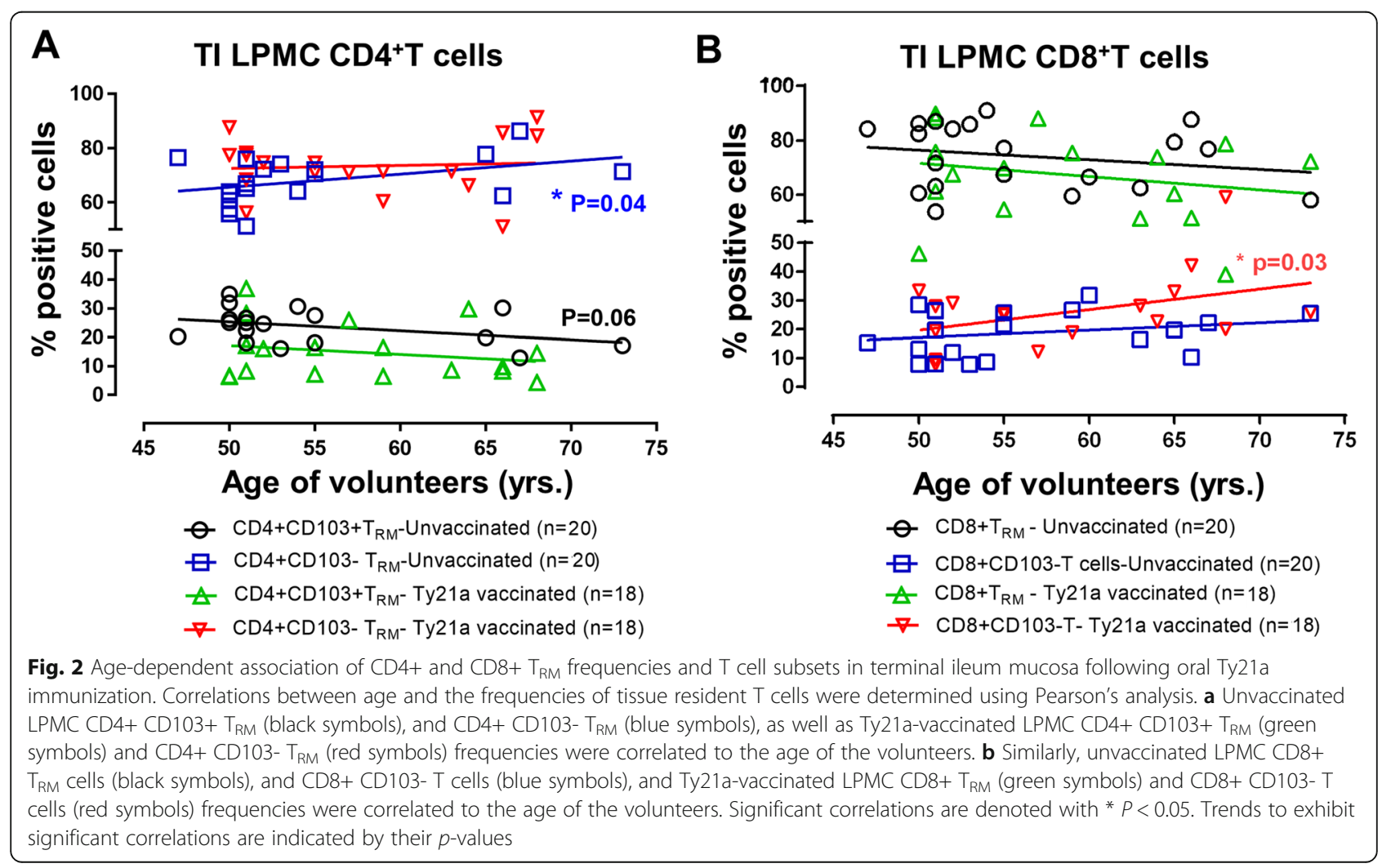


No significant associations were noted between age and these two cell subsets frequencies following Ty21a immunization (Fig. 2a). Next, we determined associations between age and $\mathrm{CD} 8+\mathrm{T}_{\mathrm{RM}}$ frequencies. No significant associations were noted between age and frequencies of CD8 $+T_{R M}$ and CD103- CD8+ T cells in unvaccinated volunteers (Fig. 2b). However, following Ty21a immunization, we observed a significant $(p=0.03)$ positive correlation between the frequencies of CD103- CD8+ T cells and age (Fig. 2b).

Multiple studies have examined $\mathrm{CD} 4: \mathrm{CD} 8$ ratios in various populations including France, Austria, Spain, USA and China and have shown either increases, decreases or no changes depending on the populations evaluated [31-34]. It is widely accepted that inverted CD4:CD8 ratios represent immune risk factors related to fewer B cells, expansion of late-differentiated or senescent $\mathrm{T}$ cells (CD8+ CD28-), and higher human cytomegalovirus (HCMV) seropositivity [35]. Of note, CD4:CD8 ratios have been usually determined in peripheral blood rather than in tissues and never following oral Ty21a immunization. Thus, we determined the CD4/CD8 ratios in both blood and terminal ileum LPMC total CD3+ T cells, as well as in CD103+ and CD103- $\mathrm{T}$ cell subsets in both unvaccinated and vaccinated volunteers. Similar to the data reported by Lin et al., 2016 [34], we observed that the ratio of CD4/CD8 in PBMC appears to increase with age in our Baltimore cohort; however, these changes did not reach statistical significance. However, no differences were observed between unvaccinated and vaccinated groups (Fig. 3a). In contrast, in TI LPMC CD3+ T cells obtained from unvaccinated volunteers, the CD4/CD8 ratios decrease with age as shown by a significantly ( $p=$ $0.01)$ negative correlation $(r=-0.466)$ (Fig. 3b). Of note, Ty21a immunization eliminated this negative correlation, suggesting that immunization elicited an influx of CD3+ $\mathrm{CD} 4+$ cells to the TI, particularly in elderly individuals (Fig. 3b). We next determined whether the effects of aging on CD4/CD8 ratios in TI LPMC were primarily the results of effects on CD103+ and/or CD103- T cells (resident T cells). We observed that in unvaccinated individuals, both CD103+ and CD103-CD3+ cells exhibited a trend ( $p=$ $0.06)$ to show negative correlations with increasing age (Fig. 3c, d). However, as noted for total CD3+ cells, oral Ty21a immunization eliminated these trends in both subsets (Fig. 3c, d). Thus, oral Ty21a immunization appears to influence the reservoir of local $\mathrm{T}$ cells in the elderly as well as in adults.

\section{Age-differences in single-expressing and multifunctional LPMC CD4+ and CD8+ $T_{E M} S$. Typhi-specific responses following Ty21a immunization}

Using the Ty21a human vaccination model, we have previously reported the induction of $S$. Typhi-specific
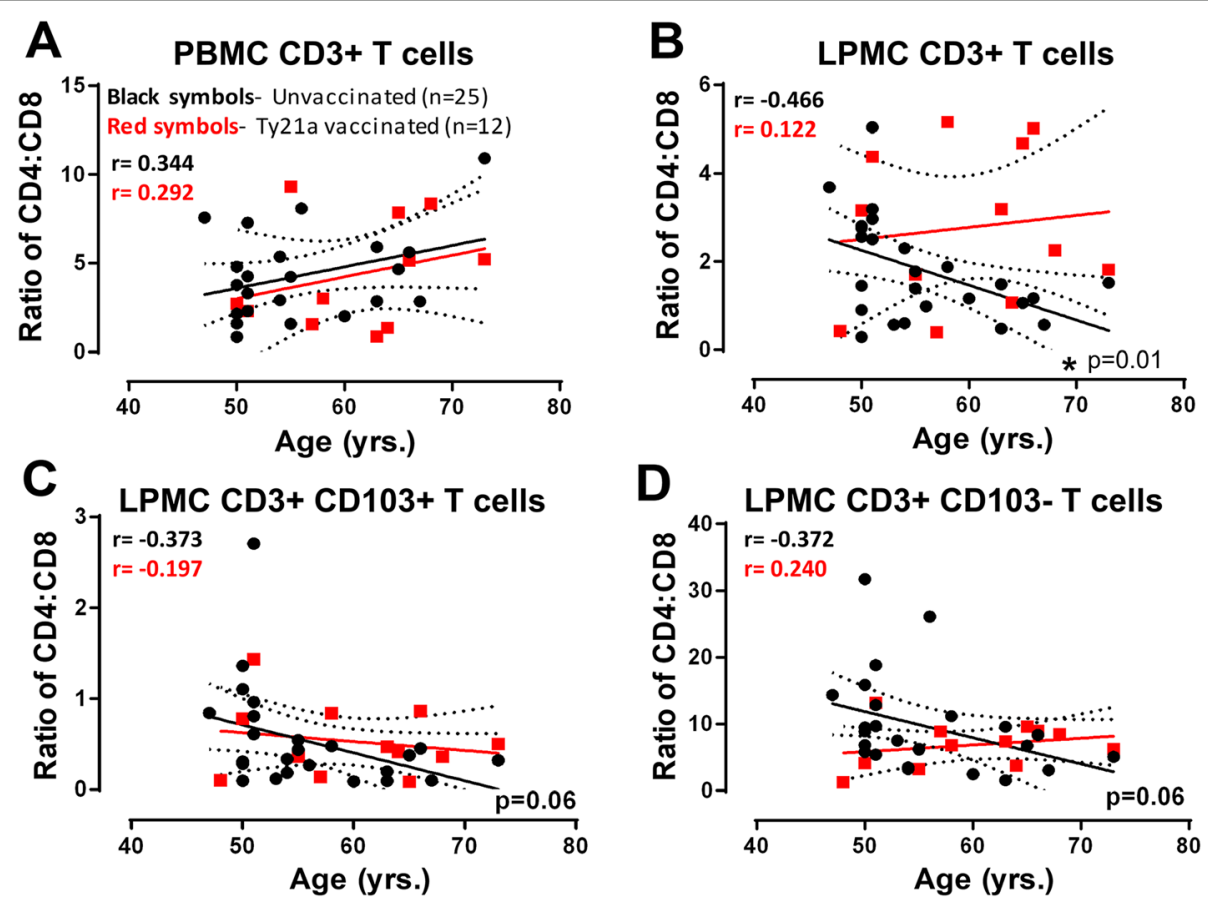

Fig. 3 Age-dependent correlation of the ratios of CD4 to CD8 cells among CD3+ T cells in peripheral blood and in CD103+ and CD103- subsets in LPMC isolated from TI biopsies. The ratio of CD4 to CD8 cells were correlated to age in (a) PBMC CD3+ T cells, (b) LPMC CD3+ T cells, (c) LPMC CD3+ CD103+ T cells and (d) LPMC CD3+ CD103- T cells. Significant correlations and trends to show correlations are indicated with * and/ or their $\mathrm{p}$-value, respectively 
responses in TI LPMC CD4+ [25] and CD8+ [36] $\mathrm{T}_{\mathrm{M}}$ subsets. However, age differences were not addressed in these studies. Because we observed altered $T_{M}$ frequencies in elderly LPMC (Figs. 1, 2 and 3), we hypothesized that LPMC S. Typhi-specific responses would also be affected in the elderly compared to adult volunteers following Ty21a immunization. To test that hypothesis, we stratified and analyzed LPMC $S$. Typhi-specific $\mathrm{T}_{M}$ subsets responses in adults ( $<60$ yrs.) and in the elderly ( $\geq 60 \mathrm{yrs}$.). Induction of antigen-specific multifunctional $\mathrm{T}$ cells have been shown to be associated with favorable disease outcome, higher effector function and higher protective efficacy after immunization compared to monofunctional $\mathrm{T}$ cells in various diseases including typhoid fever [37-41]. In addition, multifunctional and monofunctional $\mathrm{T}$ cells have been recently shown to exhibit molecular differences [42]. We have shown previously that many significant changes observed following Ty21a immunization occur, depending on the $S$. Typhispecific responses being evaluated, in single-expressing (S) and/or multifunctional (MF) LPMC CD4+ and CD8+ $\mathrm{T}_{\mathrm{EM}}$ cells $[25-28,36]$. Thus, we examined the $\mathrm{S}$ and $\mathrm{MF}$ LPMC CD4+ and CD8+ $\mathrm{T}_{\mathrm{EM}} \mathrm{S}$. Typhi-specific responses in this cohort. To this end we used the Winlist FCOM function to simultaneously analyze production of multiple cytokines/chemokines (i.e., IFN $\gamma$, TNF $\alpha$, IL-2, IL-17A, and MIP1 $\beta$ ) and expression of CD107a (a marker of cytotoxicity) in individual $S$. Typhi-specific responding cells and classified them as either single cytokine producers/CD107a expressors (S) or multifunctional (sum of double, triple, quadruple, quintuple or sextuple cytokine producers/CD107a expressors) (MF). No statistically significant differences were observed in $\mathrm{CD} 4+\mathrm{T}_{\mathrm{EM}}-\mathrm{S}$ for any of the responses evaluated following Ty21a immunization (Fig. 4a). However, we observed that LPMC CD4 $+\mathrm{T}_{\mathrm{EM}}$-MF elicited higher levels of cytokines (IFN $\gamma-p=0.1$; IL-2 $-p<0.05$; IL-17A- $p<0.05$; and MIP1 $\beta-p<0.05)$ in Ty21a-vaccinated than in unvaccinated volunteers (Fig. 4b). For LPMC CD8 $+\mathrm{T}_{\mathrm{EM}}$, we observed that Ty21a induced significant $(p<0.05)$ higher level of CD107a-S, IL-17A-MF and a trend ( $p=$ 0.1 ) for higher levels of IFN $\gamma$-MF in vaccinated than unvaccinated volunteers (Fig. 4c-d). Of note, these findings in the present cohort confirmed our previous reports in which we studied populations which included both adults ( $<60$ yrs.) and elderly ( $\geq 60$ yrs.) volunteers.

We next examined the effect of age on the characteristics and levels $S$. Typhi-specific S and MF LPMC CD4+ and $\mathrm{CD} 8+\mathrm{T}_{\mathrm{EM}}$ following Ty21a vaccination by dividing the present cohort into elderly ( $\geq 60$ yrs.) and adult $(<60$ yrs.) groups. First, we analyzed the net $S$. Typhi-specific responses of LPMC CD4 $+\mathrm{T}_{\mathrm{EM}}$ between the elderly and adult groups. Interestingly, we observed statistically significant $(p<0.05)$ lower levels of MF IFN $\gamma$, TNF $\alpha$, IL-2,
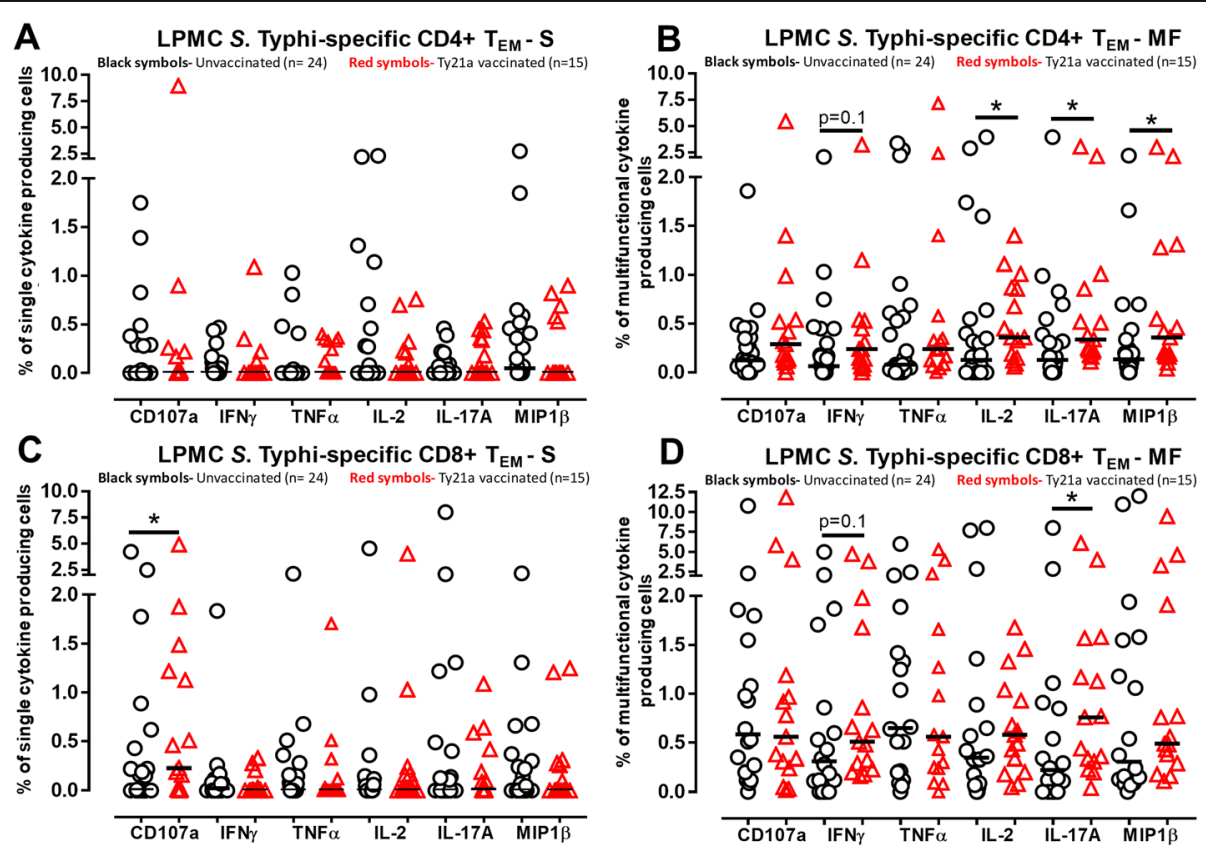

Fig. 4 Multifunctional (MF) and single-expressing (S) S. Typhi-specific CD4+ and CD8+ $T_{E M}$ responses following Ty21a immunization. Net S. Typhispecific $\mathrm{CD}^{+}$and $C D 8+T_{E M}$ responses were calculated using the FCOM function of Winlist and stratified into $\mathrm{S}$ and MF responses. Comparison of TI LPMC S. Typhi-specific (a) CD4+ $T_{E M} S$, (b) CD4+ $T_{E M} M F$, (c) CD8+ $T_{E M} S$ and (d) CD8 $+T_{E M}$ MF responses between Ty21a-vaccinated (red symbols) and unvaccinated (black symbols) volunteers were determined with significant differences shown $(* P<0.05)$. Trends to exhibit significance values are indicated by their $p$-values. Horizontal black bars represent median values 
IL-17A and expression of CD107a in the elderly than in adults following Ty21a immunization (Fig. 5a-e). In addition, we observed a trend $(p=0.07)$ to show lower responses in $\mathrm{CD} 4+\mathrm{T}_{\mathrm{EM}} \mathrm{MIP} 1 \beta+$ in the elderly compared to adult volunteers following Ty21a immunization (Fig. 5f). No statistically significant differences or trends were observed in CD4+ $\mathrm{T}_{\mathrm{EM}}-\mathrm{S}$ for CD107a, IFN $\gamma$, TNF $\alpha$, IL-17A and MIP1 $\beta$ (Fig. 5a-c, e, f). A trend $(p=0.1)$ to show decreased responses for IL-2-S was also observed in elderly as compared to adult volunteers following Ty21a immunization (Fig. 5d). Interestingly, we also observed that in unvaccinated volunteers, the levels of CD4+ $\mathrm{T}_{\mathrm{EM}} \mathrm{MF}$ were higher (IFN $\gamma(p=0.08)$; IL-17A $(\mathrm{p}<0.05)$ and MIP1 $\beta(p=0.09)$ in the elderly than in adults (Fig. 5b, e-f). Thus, we conclude that aging influences the elicited LPMC $S$. Typhi specific CD4+ T responses following Ty21a immunization.

In contrast, analysis of net $S$. Typhi-specific responses by LPMC CD8+ $\mathrm{T}_{\mathrm{EM}}$ demonstrated no statistically significant differences in the levels of MF IFN $\gamma$, TNF $\alpha$, IL-2, IL$17 \mathrm{~A}, \mathrm{MIP} 1 \beta$ or expression of CD107a between the elderly and adult individuals following Ty21a immunization (Fig. 6a-f). No statistically significant differences in CD8+ $\mathrm{T}_{\mathrm{EM}}-\mathrm{S}$ were observed for IFN $\gamma, \mathrm{TNF} \alpha, \mathrm{IL}-2, \mathrm{MIP} 1 \beta$ and expression of CD107a (Fig. 6a-d, f) except for a trend ( $p=$ $0.07)$ in IL-17A-S to exhibit higher levels in the elderly as compared to adults (Fig. 6e). In addition, we observed trends to show increases in $S$. Typhi specific CD8+ $\mathrm{T}_{\mathrm{EM}}$ (IL-17A-MF $(p=0.09)$ and CD107a-S $(p=0.09))$ in Ty21a vaccinated than in unvaccinated volunteers in adults but not in elderly volunteers (Fig. 6a-b, e). In addition, a trend $(p=0.1)$ in IFN $\gamma$-MF to exhibit higher levels in Ty21a vaccinated than unvaccinated elderly volunteers was detected (Fig. 6b).

\section{Age differences in S. Typhi-specific responses by LPMC- CD4+ $T_{R M}$ subsets following Ty21a immunization}

Tissue resident memory $\mathrm{T}$ cells contribute to local immune responses at the site of infection following infection and ultimately to protective immunity against pathogens $[43,44]$. The composition and functions of CD4+ T cells is one of the major changes observed during aging $[4,45]$. For example, classical CD4+ $\mathrm{T}$ cell subsets has been shown to be affected during the aging process by reducing their proliferation and production of IL-2 [46]. In addition, there is an increase in regulatory $\mathrm{T}$ cells $\left(\mathrm{T}_{\text {regs }}\right)$ with age that contribute to decrease responsiveness of effector $\mathrm{T}$ cells [47]. However, not much is known about the impact of aging on LPMC $T_{R M}$ particularly in the context of oral immunization. Here we took advantage of the human Ty21a immunization model to determine the effect of aging on human $\mathrm{T}_{\mathrm{RM}}$ antigen-specific responses. We first

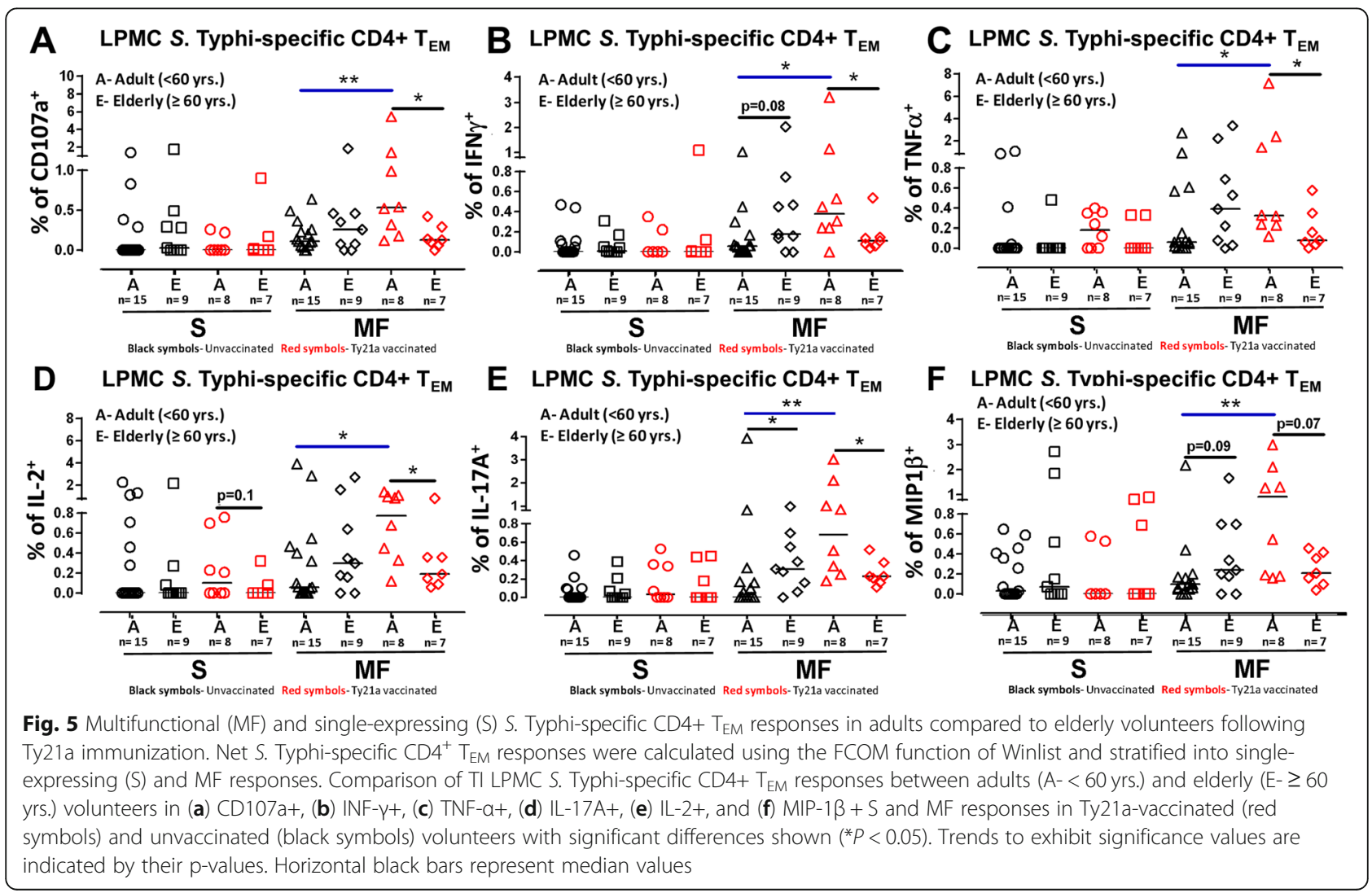



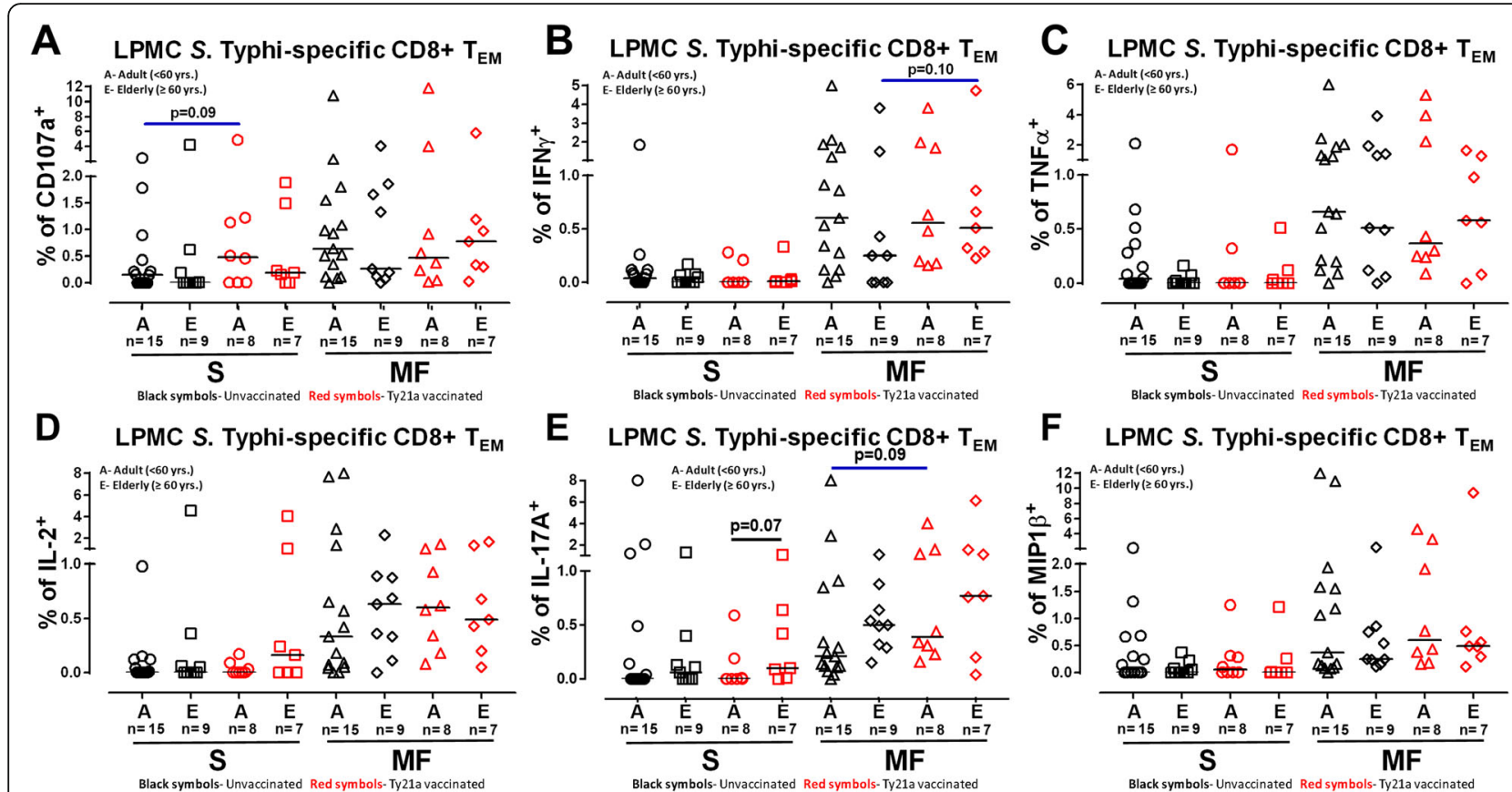

Fig. 6 LPMC multifunctional (MF) and single-expressing (S) S. Typhi-specific CD8+ TEM responses in adults compared to elderly volunteers following Ty21a immunization. Net $S$. Typhi-specific CD8+ $T_{E M}$ responses were calculated using the FCOM function of Winlist and stratified into $S$ and MF responses. Comparison of TI LPMC S. Typhi-specific CD8+ TEM responses in (a) CD107a+, (b) INF- - , (c) TNF-a+, (d) IL-17A+, (e) IL-2+, and (f) MIP-1 $\beta+S$ and MF between adults (A- $<60$ yrs.) and elderly ( $E-\geq 60$ yrs.) volunteers that were either orally vaccinated with Ty21a (red symbols) or unvaccinated (black symbols). Trends to exhibit significant values are indicated by their $p$-values. Horizontal black bars represent median values

determined the effect of aging on the responses of LPMC $\mathrm{CD} 4+\mathrm{T}_{\mathrm{RM}}$ subsets by examining net $S$. Typhi-specific responses in elderly and adult volunteers. As previously shown, using CD69 and CD103 markers, TI-LPMC CD4+ $\mathrm{T}_{\mathrm{RM}}$ are comprised of two populations, namely CD103CD69+ ( 70\%) and CD103+ CD69+ ( 20\%) (Fig. S1A). We observed that $\mathrm{CD} 103+\mathrm{CD} 4+\mathrm{T}_{\mathrm{RM}}$ showed a trend $(p=0.1)$ to exhibit decreased IL-17A responses in elderly than in adult volunteers following Ty21a immunization (Fig. 7a). In contrast, CD103- CD4+ $\mathrm{T}_{\mathrm{RM}}$ displayed significant $(p<0.05)$ decreases in the levels of IL-17A and IL-2 in the elderly compared to adults following Ty21a immunization (Fig. 7b). Of importance, significantly increased responses in adults were observed for IFN- $\gamma$ $(p<0.05)$ and IL-17A $(\mathrm{p}<0.05)$ in CD4+ CD103+ CD69+ $\mathrm{T}_{\mathrm{RM}}$ and for IL-17A $(p<0.05)$ and IL-2 $(p<$ 0.005) in CD4+ CD103- CD69+ $\mathrm{T}_{\mathrm{RM}}$ following Ty21a immunization (Fig. 7a-b).

To further investigate the differences in LPMC CD103+ and CD103- CD4+ $\mathrm{T}_{\mathrm{RM}} S$. Typhi-specific responses between the elderly and adults, we used the Winlist FCOM function to analyze multiple cytokines (i.e., IFN $\gamma$, IL-17A, IL-2, and TNF $\alpha$ ) in individual $S$. Typhi-specific responding cells and classified them as either single cytokine producer (S) or multifunctional (Sum of double, triple, and quadruple cytokine producers) (MF). First, we analyzed the net $S$. Typhi-specific
LPMC CD103+ CD4+ $\mathrm{T}_{\mathrm{RM}}$ MF responses and found no significant differences in IFN- $\gamma$, IL-17A and TNFo MF $S$. Typhi-specific responses between elderly and adult volunteers following Ty21a immunization (Table S1). However, we noted a trend $(p=0.1)$ to exhibit decreases in the production of IL-2-MF obtained from LPMC $\mathrm{CD} 103+\mathrm{CD} 4+\mathrm{T}_{\mathrm{RM}}$ in the elderly compared to adults following Ty21a immunization (Table S1). In contrast, $S$. Typhi-specific LPMC CD103+CD4+ $\mathrm{T}_{\mathrm{RM}} \mathrm{S}$ responses displayed a trend $(p=0.1)$ to show increases in IFN $\gamma$-S but decreases $(\mathrm{p}=0.1)$ in IL-17A-S in the elderly compared to adult Ty21a-vaccinated volunteers (Table S1). No significant differences in IL-2-S and TNF $\alpha-S$ production from LPMC CD103+CD4+ $\mathrm{T}_{\mathrm{RM}}$ were noted between elderly and adults following Ty21a immunization (Table S1).

Next, we analyzed the net $S$. Typhi-specific LPMC CD103- CD4+ $T_{R M}$ MF responses and found that no significant differences in IFN- $\gamma$ and TNF $\alpha$ MF $S$. Typhispecific responses between elderly and adults following Ty21a immunization (Table S1). However, we noted a trend $(p=0.1)$ to show decreases in the production of IL-17A-MF and IL-2-MF, as well as IL-17A-S in CD103$\mathrm{CD} 4+\mathrm{T}_{\mathrm{RM}}$ in the elderly compared to adult volunteers following Ty21a immunization (Table S1). No statistically significant differences in $S$. Typhi-specific IFN $\gamma$-S, IL-2-S and TNF $\alpha$-S production from LPMC CD103- 


\section{A LPMC S. Typhi-specific CD103+ CD4+ $T_{\mathrm{RM}}$}

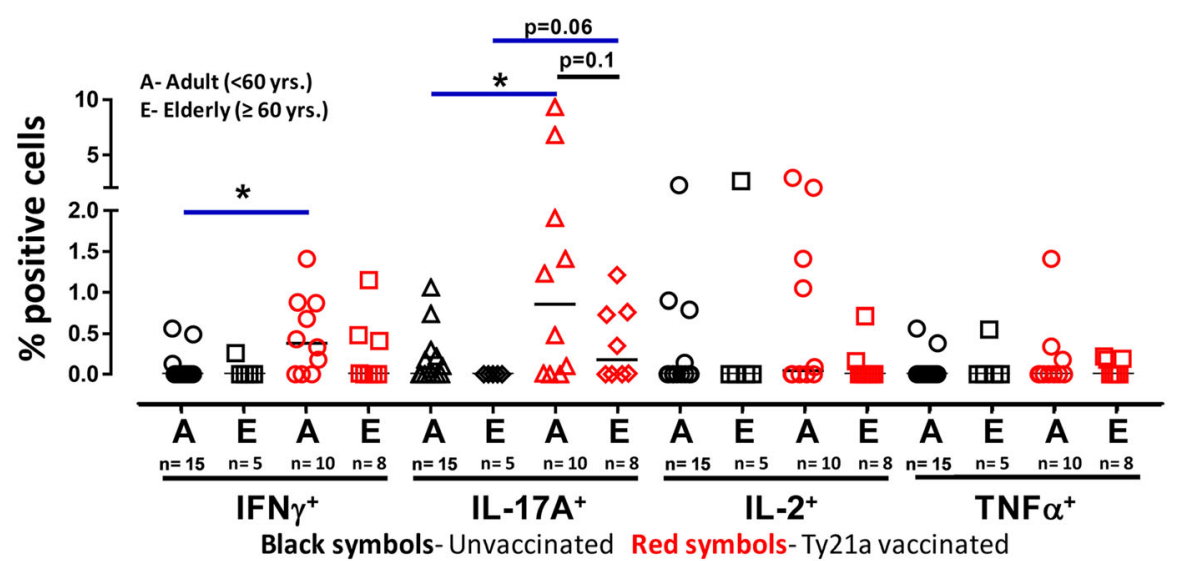

\section{B LPMC S. Typhi-specific CD103- CD4+ $\mathrm{T}_{\mathrm{RM}}$}

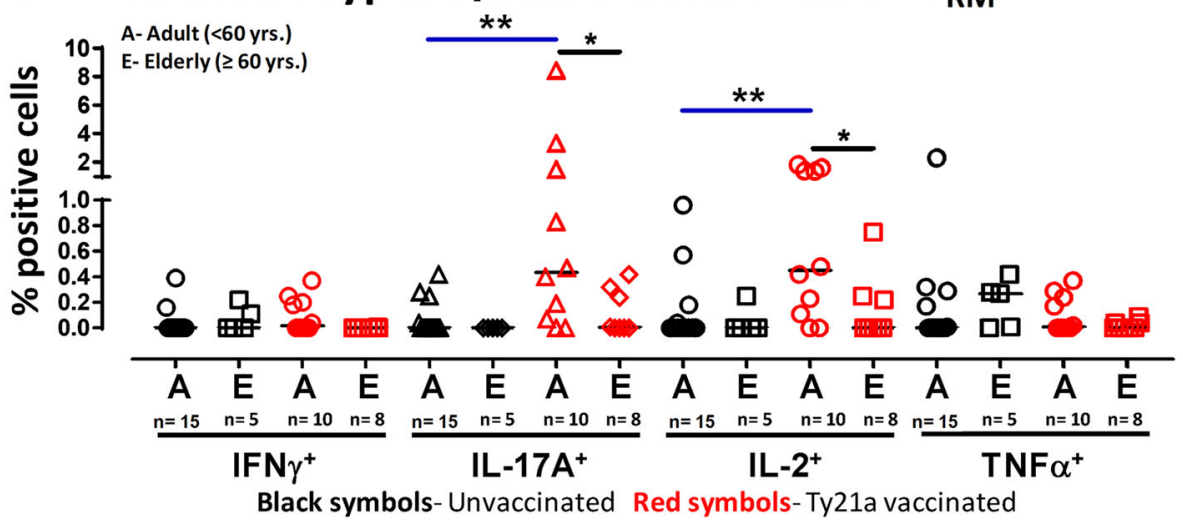

Fig. 7 S. Typhi-specific responses of TI LPMC CD69+ CD103+ CD4+ $T_{R M}$ and CD69+ CD103- CD4+ $T_{R M}$ subsets in healthy adults and elderly volunteers following oral Ty21a-immunization. The net percentages of S. Typhi-specific responses (IFNy+, IL-17A+, IL-2+, and TNFa+) in (a) CD69+ CD103+ CD4+ $T_{R M}$ and (b) CD69+ CD103- CD4+ $T_{\text {RM }}$ subsets were compared between adults ( $A-<60$ yrs.) and elderly (E- $\geq 60$ yrs.) volunteers who were either Ty21a-vaccinated (red symbols) or unvaccinated (black symbols) with significant differences $(* P<0.05)$ indicated. Trends to exhibit significance are indicated by their p-values. Horizontal bars (black) represent median values

$\mathrm{CD} 4+\mathrm{T}_{\mathrm{RM}}$ were observed among elderly and adult volunteers following Ty21a immunization (Table S1).

Interestingly, we noted that both CD4+ $\mathrm{T}_{\mathrm{RM}}$ subsets, particularly CD103- CD4 $+\mathrm{T}_{\mathrm{RM}}$, exhibited some differences in the $\alpha$-CD3/CD28 stimulation responses between elderly and adult volunteers. For example, CD4 + $\mathrm{T}_{\mathrm{RM}}$ subsets responses examined in both age groups showed that $\alpha$-CD3/CD28 beads stimulated equally well both adult and elderly CD103+CD4 $+\mathrm{T}_{\mathrm{RM}}$ to produce high multifunctional IFN $\gamma$, IL-17A, IL-2 and TNF $\alpha$ subsets in the two age groups (Table S1). Oral Ty21aimmunization did not significantly influence any of the measured cytokine responses (Table S1). Interestingly, both adult and elderly CD103- CD4 $+\mathrm{T}_{\mathrm{RM}}$ were stimulated equally well by $\alpha-C D 3 / C D 28$ beads to produce multifunctional IFN $\gamma$, IL-17A+, IL-2+ and TNF $\alpha$ MF responses (Table S1). However, CD103- CD4+ $\mathrm{T}_{\mathrm{RM}}$ showed significantly $(p<0.05)$ lower levels of IFN $\gamma-\mathrm{S}$ production, and a trend $(p=0.1)$ to exhibit lower levels of IL-17A following $\alpha$-CD3/CD28 beads stimulation in elderly than in adult Ty21a-vaccinated volunteers (Table S1). No statistically significant differences between adult and elderly volunteers were observed following stimulation of CD103- CD4+ $\mathrm{T}_{\mathrm{RM}}$ by $\alpha-\mathrm{CD} 3 / \mathrm{CD} 28$ beads in the production of IL-2 and TNF $\alpha$ (Table S1). These granular data suggest that aging and oral Ty21a-immunization have the potential to somewhat influence intrinsic differences of LPMC CD4+ $\mathrm{T}_{\mathrm{RM}}$ resulting in distinct stimulatory characteristics.

Age differences in S. Typhi-specific responses by LPMC CD8+ $T_{R M}$ subsets following Ty21a immunization In humans, the change in proportions of naïve and memory CD8+ $\mathrm{T}$ cells is a prominent feature of the 
aging process. In addition, CD8 $+\mathrm{T}$ cells among PBMC have been shown to have impaired cell proliferation, higher levels of CD57 expression (a senescence marker) and decreased cell activation markers [48]. CD8+ $\mathrm{T}_{\mathrm{RM}}$ is one of the major $\mathrm{T}$ cell subsets located in the terminal ileum (main site of infection for $S$. Typhi). However, no information is available regarding its role and contribution in the $S$. Typhi-specific responses elicited in the elderly following oral Ty21a immunization. Since we did not observe significant changes in the frequencies of LPMC CD8+ $T_{R M}$ and CD103- CD8 $+\mathrm{T}$ cells between adult and elderly, we hypothesized that both $\mathrm{CD} 8+\mathrm{T}_{\mathrm{RM}}$ and CD103- CD8+ $\mathrm{T}$ cells would respond similarly in elderly and adults following Ty21a immunization. To test this hypothesis, we compared $S$. Typhi-specific responses of $\mathrm{CD} 8+\mathrm{T}_{\mathrm{RM}}$ and $\mathrm{CD} 103-\mathrm{CD} 8+\mathrm{T}$ cells between elderly and adult volunteers following Ty21a immunization. We observed that $\mathrm{CD} 8+\mathrm{T}_{\mathrm{RM}}$ showed a trend $(p=0.1)$ to exhibit decreases in IL-17A, but not IFN $\gamma$, IL- 2 and TNF $\alpha$ production in elderly as compared to adult volunteers following Ty21a immunization (Fig. 8a). In contrast, we observed that CD103- CD8+ T cells displayed significantly $(p<0.05)$ lower levels of IL-17A, and a trend $(\mathrm{p}=0.1)$ towards lower IL-2 responses in elderly than adult volunteers following Ty21a immunization (Fig. 8b).

To further investigate the differences in LPMC CD8+ $\mathrm{T}_{\mathrm{RM}}$ and CD103- CD69+ CD8+ T cells $S$. Typhi-specific responses between elderly and adult volunteers, we analyzed the data using Winlist FCOM function as

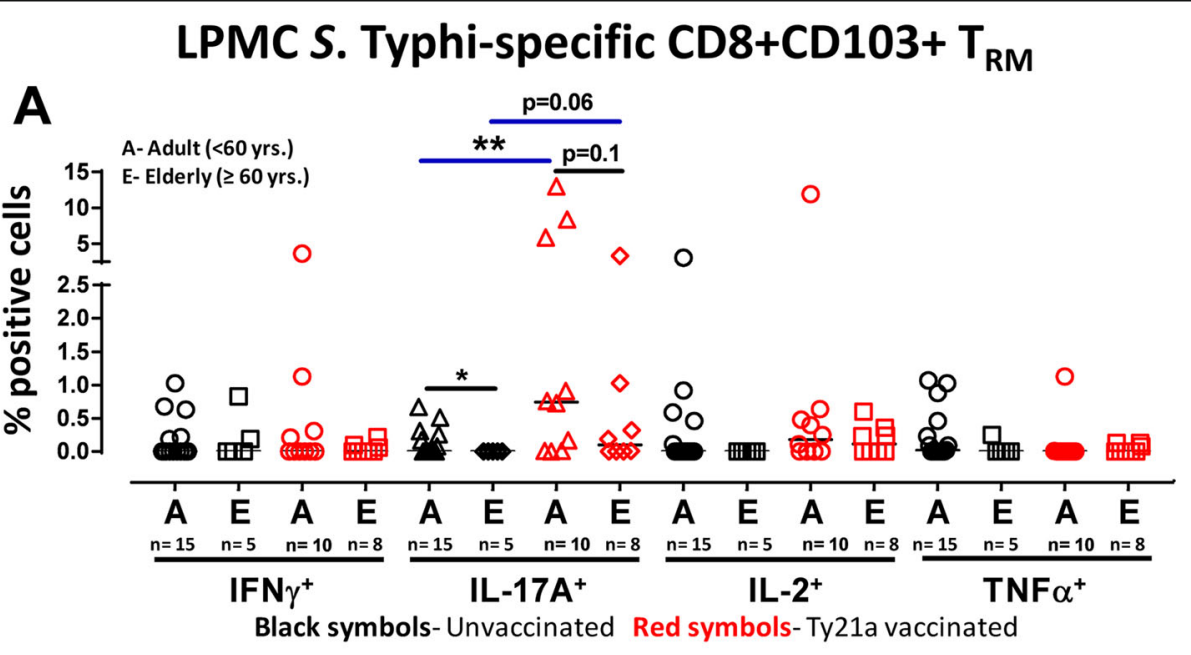

B LPMC S. Typhi-specific CD8+ CD103-T

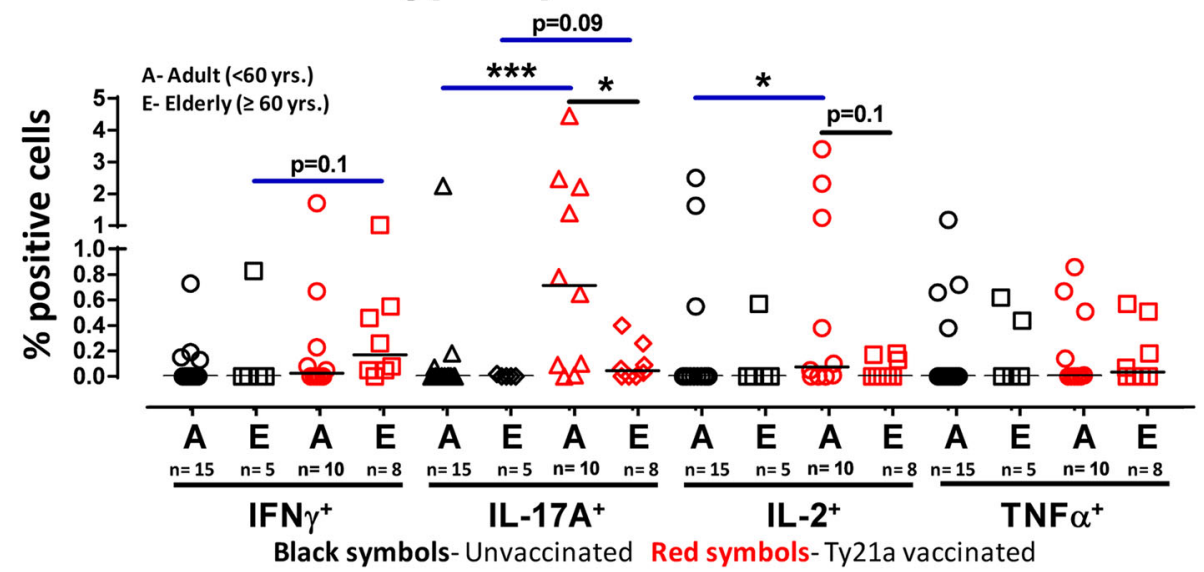

Fig. 8 S. Typhi-specific responses of terminal ileum LPMC CD8+ $T_{R M}$ and CD8+ CD69+ CD103- T cell subsets in healthy adults and elderly volunteers following oral Ty21a immunization. The net percentages of S. Typhi-specific responses (IFNy+, IL-17A+, IL-2+, and TNFa+) in (a) CD8+ $\mathrm{T}_{\mathrm{RM}}$ and (b) CD8+ CD69+ CD103- T cell subsets were compared between adults ( $\mathrm{A}-<60 \mathrm{yrs}$ ) and elderly ( $\mathrm{E}-\mathrm{z} \mathbf{6 0}$ yrs.) volunteers who were either Ty21a-vaccinated (red symbols) or unvaccinated (black symbols). Significant differences $\left({ }^{*} P<0.05 ;{ }^{*} P<0.005 ;{ }^{* *} P<0.0005\right)$ are indicated. Trends to exhibit significance are indicated by their $p$-values. Horizontal bars (black) represent median values 
described above for CD4+ $T_{R M}$ cells. First, we analyzed the net $S$. Typhi-specific LPMC CD8+ $\mathrm{T}_{\mathrm{RM}}$ MF responses and found no statistically significant differences in IFN- $\gamma$, IL-17A, IL-2 and TNF $\alpha$ MF responses between elderly and adults following Ty21a immunization (Table S2), except for a trend $(p=0.1)$ towards lower levels of IL-2 MF cells in elderly than in adults (Table S2). Additionally, LPMC CD8+ $\mathrm{T}_{\mathrm{RM}} \mathrm{S}$ responses displayed trends $(\mathrm{p}=0.1)$ to show decreased IL-17A and TNF $\alpha$ but not in IFNY and IL-2, responses in Ty21a-vaccinated elderly compared to adult volunteers (Table S2). Next, we analyzed net $S$. Typhi-specific LPMC CD103- CD8+ T S and MF responses. Significant $(p<0.05)$ decreases in IL17A-S, but not in IFN- $\gamma$, IL- 2 and TNF $\alpha$ S and MF responses were observed between elderly and adults following Ty21a immunization (Table S2).

Remarkably, we observed that following $\alpha-\mathrm{CD} 3 / \mathrm{CD} 28$ stimulation both CD8+ $\mathrm{T}_{\mathrm{RM}}$ and CD103- CD8+ T cells exhibited differences in their responses between elderly and adult volunteers. Since CD8+ CD28- T cells tend to accumulate during aging and might be present in the intestinal mucosa, we hypothesized that aging might influence the capacity of CD8+ $T_{R M}$ and CD103-CD8+ T cells to respond to stimulation. To address this hypothesis, we evaluated CD8+ $T_{R M}$ and CD103- CD8+ T cells cytokines producing cells obtained from elderly and adults volunteers following stimulation with $\alpha$-CD3/ CD28 beads.

Interestingly, $\alpha-\mathrm{CD} 3 / \mathrm{CD} 28$ beads stimulated equally well CD8+ $\mathrm{T}_{\mathrm{RM}}$ to produce high levels of IFN $\gamma$, IL-17A, IL-2 and TNF $\mathrm{S}$ and MF in adults and the elderly (Table S2), except for IL-2-S which was produced at significantly $(p<0.05)$ higher levels (Table S2) and showed a trend $(p=0.1)$ to exhibit higher levels of TNFo-S in elderly than in adult unvaccinated volunteers (Table S2). In contrast, following stimulation with $\alpha-C D 3 / C D 28$ beads, LPMC CD103- CD8+ $\mathrm{T}$ cells produced significantly $(p<0.05)$ higher levels of IFN $\gamma$ MF in elderly than in adult unvaccinated volunteers (Table S2). However, IL-17-S production by CD103- CD8 $+\mathrm{T}$ cells showed decreased levels in the elderly (trend in unvaccinated, $p=0.1$; significant in Ty21a-vaccinated, $p<0.05$ ) than in adults following stimulation with $\alpha-\mathrm{CD} 3 / \mathrm{CD} 28$ beads (Table S2). In addition, CD103- CD8+ T cells displayed trends $(p=0.1)$ to show decreases in IL-17-MF in elderly as compared to adults in Ty21a-vaccinated volunteers following $\alpha-C D 3 / C D 28$ beads stimulation (Table S2). No statistically significant differences were observed in IL-2 $\mathrm{S}$ and MF production by CD103- CD8+ T (Table S2). Of note, significantly higher TNF $\alpha$ S (" $\left.p<0.05,{ }^{* * *} p<0.005\right)$ and MF $(" p<0.05)$ responses were observed in LPMC CD103- CD8+ T cells obtained from elderly volunteers than from adult volunteers regardless of Ty21a vaccination (Table S2).

\section{HCMV status and tissue resident receptors (CD69 and CD103) expression in elderly and adults}

Because of the suggested role of human cytomegalovirus (HCMV) infection on immunosenescence [49, 50], we also determined whether HCMV seropositivity (an indicator of HCMV exposure) had an effect on $S$. Typhispecific responses in LPMC. As shown in Table S3, the levels of HCMV seropositivity in adults (<60 yrs.) were similar in all groups. In adults $<60$ yrs. we observed that $52 \%$ of unvaccinated and $50 \%$ in Ty 21 a vaccinated volunteers were seropositive for HCMV (Table S3). In the elderly ( $\geq 60$ yrs.) cohort, HCMV seropositivity was 50 and $38 \%$ in unvaccinated and Ty21a-vaccinees respectively (Table S3).

To further understand the factors that influence the differences in S. Typhi-specific responses between adults and the elderly, we compared the frequencies of LPMC $\mathrm{T}$ cells expressing CD69 or CD103 between the two groups of volunteers following Ty21a immunization or in unvaccinated. We observed no differences in the frequencies of LPMC CD4+ $\mathrm{T}_{\mathrm{EM}}$ expressing either CD69 or CD103 between adult and elderly volunteers regardless of Ty21a vaccination (Fig. S2A). However, for LPMC $\mathrm{CD} 8+\mathrm{T}_{\mathrm{EM}}$, we detected significantly $(p<0.05)$ higher levels of CD69+ CD8+ $\mathrm{T}_{\mathrm{EM}}$ cells in the elderly than in adult unvaccinated volunteers (Fig. S2B). Following Ty21a vaccination, no differences were observed in CD69+ CD8+ $\mathrm{T}_{\mathrm{EM}}$ cells between the two populations, but significant $(p<0.005)$ decreases in CD69+ CD8+ $\mathrm{T}_{\mathrm{EM}}$ cells were observed in elderly volunteers following Ty21a vaccination (Fig. S2B). Regarding CD103 expression, no statistically significant differences were noted between the two groups except for a trend $(p=0.1)$ to show decreases in the frequencies of CD103+ CD8+ $\mathrm{T}_{\mathrm{EM}}$ following Ty21a vaccination (Fig. S2B). Thus, oral Ty21a immunization influences differentially the frequencies of cells expressing CD69 and CD103 in adults and the elderly depending on the $\mathrm{T}$ cell subset.

\section{Discussion}

Age-dependent changes to the immune system have a clear impact on immune cell function, especially regarding reduced vaccine efficacy as shown by poorer vaccine-induced responses in older individuals [8-11]. Vaccine-mediated protective immunity is generally mediated through the induction of appropriate antibody and cellular immune responses (CMI). Most human studies investigating immunosenescence use cells isolated from peripheral blood (PBMC), largely due to easy accessibility. However, most of the immune cells (e.g., $\mathrm{T}_{\mathrm{RM}}$ ) reside in tissues and are functionally and phenotypically different from those present in PBMC. $\mathrm{T}_{\mathrm{RM}}$ play a crucial role in protective immunity following natural infection and their subsequent secondary exposure 
[51-53]. However, very limited information is available regarding the impact of aging on $\mathrm{T}_{\mathrm{RM}}$, particularly in the context of oral immunization (e.g., Ty21a) in the human TI. Here, we examined and compared the responses elicited by Ty21a-immunization on TI LPMC $\mathrm{T}_{M}$ and $\mathrm{T}_{\mathrm{RM}}$ subsets isolated from biopsies of elderly and adult volunteers. We showed that aging influences several immune parameters, including (i) the frequencies of CD4+ $T_{R M}$ subsets regardless of Ty21a immunization; (ii) the ratio of $\mathrm{CD} 4 / \mathrm{CD} 8$, which was found to be different in TI LPMC than in blood and that decreases with age; remarkably, Ty21a immunization increased LPMC CD4/ CD8 ratios; (iii) the frequencies of TI-LPMC CD4+ $\mathrm{T}_{\mathrm{EM}}$, which were significantly lower for $S$. Typhi-specific multifunctional responses following oral Ty21a immunization; CD8 $+\mathrm{T}_{\mathrm{EM}}$ responses were less affected than $\mathrm{CD} 4+\mathrm{T}_{\mathrm{EM}}$; (iv) the frequencies of TI-LPMC CD4+ $\mathrm{T}_{\mathrm{RM}}$ subsets, which were significantly lower than in adults for $S$. Typhi-specific IL-17A and IL-2 production following Ty21a immunization; and (v) the frequencies of TI-LPMC CD8+ $\mathrm{T}_{\mathrm{RM}}$ and CD103- CD8+ T cells, which exhibited lower proportions of $S$. Typhi-specific IL-17A and IL-2 than adults. Taken together, these results contribute major novel information of the effects of aging on human TI-LPMC $\mathrm{T}_{M}$ and $\mathrm{T}_{\mathrm{RM}}$ responses following oral Ty21a immunization.

In older individuals, alterations to $\mathrm{T}$ cell populations have been implicated in the decline of immunity. For example, the frequencies of PBMC naive $\mathrm{T}$ cells are significantly decreased in the elderly compared to younger individuals, likely as a result of thymic involution [54]. In the intestine, the frequency of naïve cells is already very low. Nevertheless, we were able to document that both TI LPMC CD4+ and CD8+ $\mathrm{T}_{\text {naive }}$ populations are significantly lower in the elderly than in adults. A similar finding was reported in the recto-sigmoid colon from elderly individuals [55]. These results indicate that alterations in $\mathrm{T}$ cell populations occur not only in blood, but also in tissues. Studies in humans have shown an increased number of memory and effector cells during aging in both peripheral blood CD4+ and CD8+ subsets [56]. Here, we observed lower levels of LPMC CD4+ (trend) and CD8+ (significant) $\mathrm{T}_{\mathrm{CM}}$, but no significant differences in the frequencies of LPMC $\mathrm{T}_{\mathrm{EM}}$ and $\mathrm{T}_{\mathrm{EMRA}}$ in unvaccinated elderly than in adults. Oral Ty21a immunization resulted in alterations of the levels of these memory subsets in the local mucosa which differed between adults and the elderly. Age-associated differences in the responses of $\mathrm{CD} 4+$ and $\mathrm{CD} 8+\mathrm{T}$ cells have been previously reported in response to vaccination against viral (e.g., influenza, yellow fever), bacterial (e.g., Streptococcus pneumonia) and parasitic (e.g., Plasmodium falciparum) infectious diseases [11, 57-60]. Our studies confirm age-associated differences in $\mathrm{CD} 4+$ and
CD8+ responses that correlate with lower vaccination efficacy in older adults $[8,61,62]$. However, most studies were performed using PBMC. In contrast, our data showing that age affects immunity following oral immunization with an attenuated oral vaccine to a major bacterial pathogen extend these findings by providing direct evidence that aging influences not only the systemic, but also mucosal vaccine-induced responses. These results suggest that oral Ty21a vaccination of older individuals may not be as efficacious as younger adults, due, at least in part, to the observed reductions in Th17 effectors, an important component of immunity in mucosal surfaces. Interestingly, our data indicate that $C D 4+T_{E M}$ and $T_{R M}$ vaccineinduced responses are the major subsets in the TI mucosa impacted by aging, both in terms of quantity (frequencies) and characteristics of the responses. For example, oral Ty21a immunization elicits significantly lower multifunctional CD4+ $\mathrm{T}_{\mathrm{EM}}$ (CD107a, IFN $\gamma$, IL-17A, IL-2, TNF $\alpha$ and MIP1 $\beta$ ) responses in the elderly than younger adults. Similar observations were recorded in the production of IL-17A and IL-2 from elderly CD4+ $\mathrm{T}_{\mathrm{RM}}$ subsets. Lower levels of $S$. Typhi-responses (e.g., IL-17A and IL-2) were also observed in TI-LPMC CD8+ $\mathrm{T}_{\mathrm{RM}}$ and CD103-CD8+ $\mathrm{T}$ cells obtained from elderly subjects. While most $S$. Typhi-specific responses were lower in elderly than adult volunteers, this did not seem to be due to an intrinsic factor of cells in the elderly, since they were capable of responding to stimulation. For example, following $\alpha-C D 3 /$ CD28 stimulation, we observed that all cytokines evaluated (IFN $\gamma$, IL-17A, IL-2 and TNF $\alpha$ ) produced by CD4+ $\mathrm{T}_{\mathrm{RM}}$ were similar in elderly and adults. One caveat in our study is that the median age difference between the two age groups (e.g., $<60$ and $\geq 60$ yrs.) is 11 years in the unvaccinated group and 15 years in Ty21a-vaccinees. This is due to the fact that routine indicated colonoscopies in health adults are medically indicated after the age of 45 . It is likely that $\mathrm{T}_{\mathrm{RM}}$ obtained from terminal tissues of younger adults (18-45 yrs) might have shown even larger differential responses between elderly and young adult volunteers. Taken together, these data provide evidence that aging decreased Ty21a vaccine-induced responses not only systemically but also in the gut, the preferred site of entry of $S$. Typhi. Of note, these impaired responses are not due to LPMC $\mathrm{T}$ cells not being able to produce cytokines since the $\mathrm{CD} 3$ activation pathway and the main costimulatory pathway (CD28) appear to be functioning similarly in adults and the elderly. Future studies are needed to elucidate the mechanisms operating in the local mucosa that are hampering vaccine-induced responses.

$\mathrm{T}_{\mathrm{RM}}$ are now considered essential components of immunological memory as numerous reports have demonstrated the important roles of $\mathrm{T}_{\mathrm{RM}}$ in mediating protective immunity $[17,18]$. Human intestinal $\mathrm{T}_{\mathrm{RM}}$ are established early in childhood and increase in frequency 
throughout adulthood [63]. In the elderly population, $\mathrm{T}_{\mathrm{RM}}$ frequencies are high and stable in the intestine where they are mostly found in the lamina propria and intraepithelial lymphocyte compartments (IEL) [63]. Here, we extend these finding by showing that LPMC $\mathrm{CD} 4+\mathrm{T}_{\mathrm{RM}}$ subsets are influenced by aging, particularly in terms of higher frequencies of CD103- CD4+ $T_{R M}$ but lower effector responses, especially IL-17A and IL-2, in elderly volunteers following Ty21a immunization. On the other hand, CD8+ $\mathrm{T}_{\mathrm{RM}}$ and CD103- CD8+ T cells showed no differences in the number of cells present in the mucosa, but also exhibited significantly reduced IL17A and IL-2 responses in elderly volunteers. While it is difficult to assess the lifespan and tissue retention of human $T_{R M}$ over time in vivo, studies of the age-associated changes in human $T_{R M}$ have been performed in other tissues (e.g., lungs) to determine $\mathrm{T}_{\mathrm{RM}}$ responses to pathogens, especially viruses. Of note, our observations of age-associated changes in the intestine following Ty21a vaccination are consistent with those reported in the literature in other tissues. For example, a recent study investigated how lung CD8 $+\mathrm{T}_{\mathrm{RM}}$ are affected by aging and how they respond in vitro to exposure to influenza and SARS-CoV-2 [64]. Interestingly, the authors reported that lung $C D 8+T_{M}$ are very susceptible to ageassociated attrition and showed that CD8+ CD103+ CD69+ $\mathrm{T}_{\mathrm{RM}}$ influenza-specific cells declined with age while CD8+ CD69- CD103- $\mathrm{T}$ frequencies increases [64]. In contrast, unlike exposure to influenza, exposure of lung CD8 $+\mathrm{T}_{\mathrm{M}}$ cells (including $\mathrm{T}_{\mathrm{RM}}$ ) to SARS-CoV-2 did not elicit the induction of pro-inflammatory cytokines (including Type I, II and III interferon) irrespective of the age of the volunteers [64]. Of note, these volunteers were naive to SARS-CoV-2 and presumably would not have any SARS-CoV-2-specific $\mathrm{T}_{\mathrm{RM}}$ in the lungs. Taken together, these data suggest that $\mathrm{T}_{\mathrm{RM}}$ subsets are retained in the local mucosa as we age, but their characteristics, functions and numbers of some its subsets are affected. Future studies are needed to address ageassociated changes in the $\mathrm{T}$ cell compartment in specific segments of the gastrointestinal and respiratory tracts, subset-specific dynamics and their characteristics in order to elucidate $T_{R M}$ 's potential as targets for future vaccines.

Recent data have suggested that impaired vaccineinduced immunity in the elderly is associated with inflammaging and immunosenescence [65, 66]. HCMV is considered a major contributor to inflammaging, which is generally asymptomatic in healthy individuals [67]. About $25-90 \%$ of the world wide population is HCMV seropositive, with higher prevalence in older adults $[68,69]$. The establishment of a latent infection by HCMV is a common event likely correlated to immunosenescence by increasing the levels of highly differentiated effector memory cells in the CD8+ and $\mathrm{CD} 4+\mathrm{T}$-cell pools [70]. It has been reported that the presence of increased numbers of specific $\mathrm{T}_{\text {reg }}$ and $\mathrm{T}$ follicular helper cells during HCMV infection limits the efficacy of influenza vaccination in older people, likely through rendering less capable to provide help to B cells when faced with new antigens [71]. In contrast, it has been reported that HCMV infection does not appear to influence the rate of change of various lymphocytes (e.g., $\mathrm{T}$ and NK cells) [34]. In our study, we observed that similar percentages in all groups were seropositive for HCMV. Moreover, when we compared $S$. Typhi-specific IL-17A responses between HCMV positive and negative individuals in both Ty21a vaccinated and unvaccinated volunteers, we observed no significant differences between these two groups. Thus, HCMV seropositivity did not appear to be a major determinant of the age-related dissimilarities observed in $S$. Typhi-specific vaccineinduced responses. However, these observations could be due to the relatively low number of volunteers, health status and age range of our volunteers ( $47-73$ yrs.). Further studies will need to address HCMV-specific memory $\mathrm{T}_{\mathrm{RM}}$ responses and their correlation with the TCR repertoire and clonal expansion of $\mathrm{T}$ cell subsets induced by Ty21a immunization.

\section{Conclusion}

Similar to infant vaccination schedules, the elderly population would benefit from highly effective bacterial vaccines, particularly those targeted to common and serious infections caused by pathogens such as S. pneumoniae, E. coli, S. aureus, C. difficile, K. pneumoniae and Mtb. These vaccines might be more effective if tailored to optimally elicit immunity at the site of infection (e.g., mucosal surfaces of the respiratory and gastrointestinal tracts) and utilized the protective potential of $\mathrm{T}_{\mathrm{RM}}$ to express the appropriate immune correlated of protection against these pathogens. Here, we provide the first evidence of age-associated differences of the induction of tissue resident CD4+ and $\mathrm{CD} 8+\mathrm{T}_{\mathrm{RM}}$ following Ty21a immunization. These results contribute novel insights in our understanding of the effect of aging on immune cells in human tissues and the generation of mucosal immunity in the elderly following immunization with oral attenuated bacteria.

\section{Methods}

\section{Volunteers, immunization and sample collection}

Individuals (aged 49-74 yrs) undergoing routine colonoscopy were enrolled from the Baltimore-Washington metropolitan area and University of Maryland, Baltimore campus. Volunteers who have no previous history of typhoid fever and were not vaccinated with the attenuated oral Ty21a typhoid vaccine were assigned to each of two groups. Four recommended doses of Ty21a (Vivotif 
enteric-coated capsules; Crucell, Bern, Switzerland) [72] were administered to the first group (Adult $(<60 \mathrm{yrs}) n=$ 10; Elderly ( $\geq 60$ yrs) $n=8$ ) but not to the control group (Adult $n=21$; Elderly $n=8$ ). Blood samples were collected 14-21 days before colonoscopy (pre-immunization) for the purpose of generating autologous EBV-B cell lines to be used in the $S$. Typhi-specific assays. The day of the colonoscopy (day $0 ; 14$ to 21 days post vaccination), large capacity forceps were used to obtain terminal ileum biopsies [26]. PBMC were isolated immediately after blood draws by density gradient centrifugation and cryopreserved in liquid nitrogen following standard techniques [73].

\section{Isolation of lamina propria mononuclear cells (LPMC) from terminal ileum biopsies}

TI-LPMC was freshly isolated as previously described [26, 74-76]. Briefly, after collection of biopsies from volunteers undergoing routine colonoscopy, tissues were treated with HBSS (without $\mathrm{CaCl}_{2}, \mathrm{MgCl}_{2}, \mathrm{MgSO}_{4}$; Gibco, Carlsbad, $\mathrm{CA}$ ) and EDTA (10 mM; Ambion, Grand Island, NY) and were vigorously shaken for $45 \mathrm{~min}$ to remove IEL. Next, the biopsies were digested enzymatically with collagenase D $(100 \mu \mathrm{g} / \mathrm{mL}$; Roche, Indianapolis, IN) and DNase I $(10 \mu \mathrm{g} /$ mL; Affymetrix, Cleveland, OH) for 45 mins followed by homogenization using a Bullet Blender homogenizer (Next Advance Inc., Averill, NY) to extract LPMC. LPMC were either stained immediately for immunophenotyping by flow cytometry or stimulated overnight.

\section{Target cell preparation and $S$. Typhi infection}

Autologous Epstein-Barr virus (EBV)-transformed lymphoblastoid cell line (EBV-B cells) were generated from each participant's pre-immunization PBMC as previously described [73, 77]. Target cells were then infected with wt-S. Typhi strain ISP1820 at a MOI of 7:1 as previously described [25]. Infected target cells were then gammairradiated $(6000 \mathrm{rad})$ before ex vivo LPMC stimulation. To confirm $S$. Typhi infection, target cells were stained with anti-Salmonella common structural Ag (CSA-1, Kierkegaard and Perry, Gaithersburg, MD) and analyzed by flow cytometry as previously described $[73,77]$.

\section{Stimulation of terminal ileum LPMC}

Freshly isolated TI-LPMC were used as effector cells as previously described $[25,26]$. Briefly, LPMC were cocultured, respectively, with either non-infected or $S$. Typhi-infected EBV-B (MOI of 7:1). LPMC cultured with media only or in the presence of $\alpha-\mathrm{CD} 3 / \mathrm{CD} 28$ (Life technologies, Grand Island, NY) were used as negative and positive controls, respectively. After $2 \mathrm{~h}, 0.5 \mu \mathrm{l}$ of Golgi Stop (Monensin, BD) and $0.5 \mu \mathrm{l}$ Golgi Plug (Brefeldin A, $\mathrm{BD}$ ) were added and cultures continued overnight at $37^{\circ} \mathrm{C}$ in $5 \% \mathrm{CO}_{2}$.

\section{Surface and intracellular staining}

Following overnight stimulation, TI LPMC were stained for flow cytometry analysis as previously described [26]. Briefly, LPMC were stained for live/dead discrimination (YEVID) (Invitrogen, Carlsbad, CA) and then the Fc receptors were blocked using human immunoglobulin $(3 \mu \mathrm{g} / \mathrm{mL}$; Sigma). This was followed by surface staining. Briefly, for the LPMC $\mathrm{T}_{\mathrm{RM}}$ panel, cells were stained at $4{ }^{\circ} \mathrm{C}$ for $30 \mathrm{~min}$ with fluorescently labeled monoclonal antibodies (mAbs) directed to CD13-Pacific Orange (conjugated in-house), CD19-BV570 (HIB19, Biolegend, San Diego, CA), CD3BV650 (OKT3, Biolegend), CD4-PE-Cy5 (RPA-T4, BD), CD8-PerCP-Cy5.5 (SK1, BD), CD45RA-biotin (HI100, BD), CD62L-APC-A780 (DREG-56, eBioscience, San Diego, CA), and CD103-FITC (Ber-ACT8, BD). After a wash, cells were stained with streptavidin (SAV)-Qdot800 (Invitrogen) at $4{ }^{\circ} \mathrm{C}$ for $30 \mathrm{~min}$. Cells were then fixed and permeabilized using IC fixation and permeabilization buffers $(8222 / 8333$, eBioscience). This was followed by staining at $4{ }^{\circ} \mathrm{C}$ overnight with mAbs directed to interleukin (IL)-17A-BV421 (BL168, Biolegend), interferon (IFN)- $\gamma$-PE-Cy7 (B27, BD), tumor necrosis factor (TNF)- $\alpha$-Alexa 700 (MAb11, BD), CD69-ECD (TP1.55.3, Beckman Coulter, Danvers, MA), and IL-2-BV605 (MQ1-17H12, Biolegend). For the LPMC $\mathrm{T}_{\mathrm{EM}}$ panel, cells were stained with fluorescently labeled mAbs directed to CD19-BV570 (HIB19, BioLegend), CD13-Pacific Orange (conjugated in-house), CD3-BV650 (OKT3, BioLegend), CD4-PE-Cy5 (RPA-T4, BD), CD8PerCP-Cy5.5 (SK1, BD), CD45RA-biotin (HI100, BD), CD62L-APC-A780 (DREG-56, eBioscience) and integrin $\alpha 4 \beta 7$-A647 (ACT1; conjugated in-house) at $4{ }^{\circ} \mathrm{C}$ for 30 $\mathrm{min}$. As for the $\mathrm{T}_{\mathrm{RM}}$ panel, cells were stained with streptavidin (SAV)-Qdot800 (Invitrogen) at $4{ }^{\circ} \mathrm{C}$ for $30 \mathrm{~min}$. Cells were then fixed and permeabilized using IC fixation and permeabilization buffers $(8222 / 8333$, eBioscience). This was followed by staining $\left(4^{\circ} \mathrm{C}\right.$ overnight) with $\mathrm{mAbs}$ directed to IL-17A-BV421 (BL168, BioLegend), IFNy-PE-Cy7 (B27, BD), TNFa-Alexa 700 (MAb11, BD), and CD69-ECD (TP1.55.3, Beckman Coulter, Danvers, MA, USA), IL-2BV605 (MQ1-17H12, BioLegend), and MIP1/-PE (IC271P, R\&D Systems). After staining, cells were stored in 1\% paraformaldehyde at $4{ }^{\circ} \mathrm{C}$ until data collection. Data were collected using a customized LSRII flow cytometer (BD) and then analyzed using the WinList version 7 (Verity Software House, Topsham, ME) software package. S. Typhi-specific responses were expressed as net percentage of positive cells (background after stimulation with uninfected cells were subtracted from values obtained with $S$. Typhi-infected targets). The FCOM function of WinList was used to determine $S$. Typhi-specific MF responses in TI LPMC. Flow cytometry experiments were performed at the Flow Cytometry and Mass Cytometry Core Facility of the University of Maryland School of Medicine Center for Innovative Biomedical Resources (CIBR), Baltimore, Maryland. 


\section{HCMV ELISA}

The volunteers' sera were kept frozen at $-20^{\circ} \mathrm{C}$ until testing for HCMV specific IgG by enzyme-linked immunoassay (GenWay Biotech Inc., San Diego, CA) which was performed according to the manufacturer's instructions. A corrected absorbance value of 0.25 was considered positive.

\section{Statistical analysis}

Data were analyzed using the statistical software GraphPad Prism $^{\text {Tw }}$ version 7 (Graphpad, San Diego, CA, USA). Statistical differences in median values between two groups were determined using Mann-Whitney tests. Correlations (Age versus frequencies of $T_{R M}$ and $T_{E M}$ ) were evaluated using Pearson's correlation tests. Based on a recent recommendation by the American Statistical Association (ASA), particularly when analyzing data sets with relatively low numbers of volunteers, we also indicated trends in expression of markers or cytokine responses where appropriate using a $P \leq 0.1[32,33]$.

\section{Abbreviations}

PBMC: Peripheral blood mononuclear cells; LPMC: Lamina propria mononuclear cells; $\mathrm{T}_{\mathrm{RM}}$ : Tissue resident memory T cell; EBV-B: Epstein-Barr virus (EBV)-transformed lymphoblastoid B cells; MF: S. Typhi-specific multifunctional cells; S: S. Typhi-specific single cytokine producing cells; TI: Terminal ileum; $T_{\text {EM: }}$ T-effector/memory- (CD62L- CD45RA-); TCM: T-central/ memory - (CD62L+ CD45RA-); $T_{\text {EMRA: }}$ TEM-CD45RA+ - (CD62L- CD45RA+); LP: Lamina propria

\section{Supplementary Information}

The online version contains supplementary material available at https://doi. org/10.1186/s12979-021-00227-y.

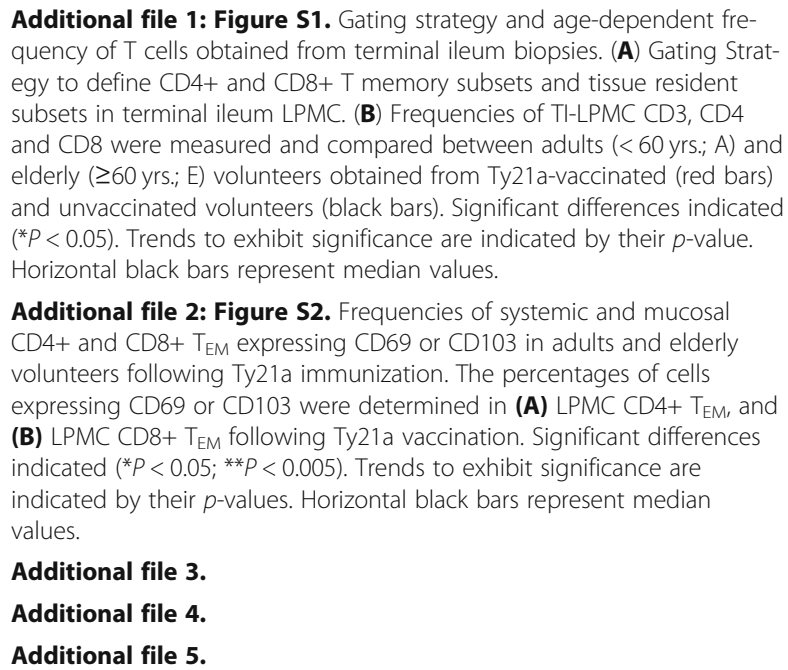
quency of T cells obtained from terminal ileum biopsies. (A) Gating Strategy to define CD4+ and CD8+ T memory subsets and tissue resident subsets in terminal ileum LPMC. (B) Frequencies of TI-LPMC CD3, CD4 and CD8 were measured and compared between adults ( $<60$ yrs.; A) and elderly ( $\geq 60$ yrs.; E) volunteers obtained from Ty21a-vaccinated (red bars) and unvaccinated volunteers (black bars). Significant differences indicated $\left({ }^{*} P<0.05\right)$. Trends to exhibit significance are indicated by their $p$-value. Horizontal black bars represent median values.

Additional file 2: Figure S2. Frequencies of systemic and mucosal CD4+ and CD8+ $\mathrm{T}_{\mathrm{EM}}$ expressing CD69 or CD103 in adults and elderly volunteers following Ty21a immunization. The percentages of cells expressing CD69 or CD103 were determined in (A) LPMC CD4+ $T_{E M}$, and (B) LPMC CD8+ $T_{E M}$ following Ty21a vaccination. Significant differences indicated $\left({ }^{*} P<0.05 ;{ }^{*} P<0.005\right)$. Trends to exhibit significance are indicated by their $p$-values. Horizontal black bars represent median values.

Additional file 3.

Additional file 4.

Additional file 5 .

\section{Acknowledgments}

We are indebted to the volunteers who allowed us to perform this study. We thank the staff from the Recruiting Section of Center for Vaccine Development for their help in collecting TI biopsies and blood specimens; Mr. Jeffery Floyd for isolating PBMC and Ms. Regina Harley and Catherine Storrer for excellent technical assistance in the performance of the flow cytometric determinations.

\section{Authors' contributions}

JSB performed the experiments, contributed to study design, acquisition of data, analysis and drafting of the manuscript; SAP performed endoscopies, obtained terminal ileum biopsies and reviewed the manuscript; RB contributed to patient recruitment, collection of PBMC and terminal ileum biopsies and reviewed the manuscript; EG performed endoscopies, obtained terminal ileum biopsies and reviewed the manuscript; BDG, performed endoscopies, obtained terminal ileum biopsies and reviewed the manuscript; MBS designed the study, supervised the work and drafted the manuscript. The author(s) read and approved the final manuscript.

\section{Funding}

This work was funded by NIAID, NIH, DHHS grants R01-AI036525, U19Al082655 (Cooperative Center for Human Immunology [CCHI]), U19-Al109776 (Center of Excellence for Translational Research [CETR] and U19 Al142725. The content is solely the responsibility of the authors and does not necessarily represent the official views of the National Institute of Allergy and Infectious Diseases or the National Institutes of Health.

\section{Availability of data and materials}

The datasets supporting the findings of this study are available within the article and its Supplementary Information files.

\section{Declarations}

Ethics approval and consent to participate

Written informed consent was obtained from subjects and all procedures were approved by the University of Maryland, Baltimore Institutional Review Board (IRB) and registered on ClinicalTrials.gov (identifier NCT03970304). The study was conducted in accordance with the principles of the International Conference of Harmonization Good Clinical Practice guidelines.

\section{Consent for publication}

Not applicable.

\section{Competing interests}

The authors declared no conflict of interest.

\section{Author details}

${ }^{1}$ Center for Vaccine Development and Global Health, University of Maryland School of Medicine, Baltimore, MD 21201, USA. ²Department of Pediatrics, University of Maryland School of Medicine, Baltimore, MD, USA. ${ }^{3}$ Department of Medicine, University of Maryland School of Medicine, Baltimore, MD, USA. ${ }^{4}$ Division of Gastroenterology and Hepatology, University of Maryland School of Medicine, Baltimore, MD, USA. ${ }^{5}$ Program in Oncology, University of Maryland Marlene and Stewart Greenebaum Comprehensive Cancer Center, Baltimore, MD 21201, USA.

Received: 10 September 2020 Accepted: 16 March 2021

Published online: 19 April 2021

\section{References}

1. Aw D, Silva $A B$, Palmer DB. Immunosenescence: emerging challenges for an ageing population. Immunology. 2007;120(4):435-46. https://doi.org/1 0.1111/j.1365-2567.2007.02555.x.

2. Bektas A, Schurman SH, Sen R, Ferrucci L. Human T cell immunosenescence and inflammation in aging. J Leukoc Biol. 2017;102(4):977-88. https://doi. org/10.1189/jlb.3RI0716-335R.

3. Scholz JL, Diaz A, Riley RL, Cancro MP, Frasca D. A comparative review of aging and B cell function in mice and humans. Curr Opin Immunol. 2013; 25(4):504-10. https://doi.org/10.1016/j.coi.2013.07.006.

4. Nikolich-Zugich J. Aging of the T cell compartment in mice and humans: from no naive expectations to foggy memories. J Immunol. 2014;193(6): 2622-9. https://doi.org/10.4049/jimmunol.1401174.

5. Gozalo PL, Pop-Vicas A, Feng Z, Gravenstein S, Mor V. Effect of influenza on functional decline. J Am Geriatr Soc. 2012;60(7):1260-7. https://doi.org/1 0.1111/j.1532-5415.2012.04048.x.

6. Johnson RW, Bouhassira D, Kassianos G, Leplege A, Schmader KE, Weinke T. The impact of herpes zoster and post-herpetic neuralgia on quality-of-life. BMC Med. 2010;8(1):37. https://doi.org/10.1186/1741-7015-8-37. 
7. Wroe PC, Finkelstein JA, Ray GT, Linder JA, Johnson KM, Rifas-Shiman S, Moore MR, Huang SS. Aging population and future burden of pneumococcal pneumonia in the United States. J Infect Dis. 2012;205(10): 1589-92. https://doi.org/10.1093/infdis/jis240.

8. Wagner A, Garner-Spitzer E, Jasinska J, Kollaritsch H, Stiasny K, Kundi M, Wiedermann U. Age-related differences in humoral and cellular immune responses after primary immunisation: indications for stratified vaccination schedules. Sci Rep. 2018;8(1):9825. https://doi.org/10.1038/s41598-018-2 8111-8.

9. Tseng HF, Harpaz R, Luo Y, Hales CM, Sy LS, Tartof SY, Bialek S, Hechter RC, Jacobsen SJ. Declining effectiveness of herpes zoster vaccine in adults aged >/=60 years. J Infect Dis. 2016;213(12):1872-5. https://doi.org/10.1093/infdis/ jiw047.

10. Edelman R, Deming ME, Toapanta FR, Heuser MD, Chrisley L, Barnes RS, Wasserman SS, Blackwelder WC, Handwerger BS, Pasetti M, Siddiqui KM, Sztein MB. The SENIEUR protocol and the efficacy of hepatitis B vaccination in healthy elderly persons by age, gender, and vaccine route. Immun Ageing. 2020;17(1):9. https://doi.org/10.1186/s12979-020-00179-9.

11. Chen WH, Kozlovsky BF, Effros RB, Grubeck-Loebenstein B, Edelman R, Sztein MB. Vaccination in the elderly: an immunological perspective. Trends Immunol. 2009;30(7):351-9. https://doi.org/10.1016/j.it.2009.05.002.

12. Yanes RE, Gustafson CE, Weyand CM, Goronzy JJ. Lymphocyte generation and population homeostasis throughout life. Semin Hematol. 2017:54(1):338. https://doi.org/10.1053/j.seminhematol.2016.10.003.

13. Kim C, Fang F, Weyand CM, Goronzy JJ. The life cycle of a T cell after vaccination - where does immune ageing strike? Clin Exp Immunol. 2017; 187(1):71-81. https://doi.org/10.1111/cei.12829.

14. Siegrist CA, Aspinall R. B-cell responses to vaccination at the extremes of age. Nat Rev Immunol. 2009;9(3):185-94. https://doi.org/10.1038/nri2508.

15. Del Giudice G, Goronzy JJ, Grubeck-Loebenstein B, Lambert PH, Mrkvan T, Stoddard JJ, et al. Fighting against a protean enemy: immunosenescence, vaccines, and healthy aging. NPJ Aging Mech Dis. 2018;4(1):1. https://doi. org/10.1038/s41514-017-0020-0.

16. Quinn KM, Fox A, Harland KL, Russ BE, Li J, Nguyen THO, Loh L, Olshanksy M, Naeem H, Tsyganov K, Wiede F, Webster R, Blyth C, Sng XYX, Tiganis T, Powell D, Doherty PC, Turner SJ, Kedzierska K, la Gruta NL. Age-related decline in primary CD8(+) T cell responses is associated with the development of senescence in virtual memory CD8(+) T cells. Cell Rep. 2018;23(12):3512-24. https://doi.org/10.1016/j.celrep.2018.05.057.

17. Thome JJ, Farber DL. Emerging concepts in tissue-resident T cells: lessons from humans. Trends Immunol. 2015;36(7):428-35. https://doi.org/10.1016/j. it.2015.05.003.

18. Mueller SN, Mackay LK. Tissue-resident memory T cells: local specialists in immune defence. Nat Rev Immunol. 2016;16(2):79-89. https://doi.org/10.103 8/nri.2015.3

19. Kumar BV, Ma W, Miron M, Granot T, Guyer RS, Carpenter DJ, Senda T, Sun $X$, Ho SH, Lerner H, Friedman AL, Shen Y, Farber DL. Human tissue-resident memory $T$ cells are defined by Core transcriptional and functional signatures in lymphoid and mucosal sites. Cell Rep. 2017;20(12):2921-34. https://doi.org/10.1016/j.celrep.2017.08.078.

20. Sathaliyawala T, Kubota M, Yudanin N, Turner D, Camp P, Thome JJ, et al. Distribution and compartmentalization of human circulating and tissueresident memory T cell subsets. Immunity. 2013;38(1):187-97. https://doi. org/10.1016/j.immuni.2012.09.020.

21. Watanabe R, Gehad A, Yang C, Scott LL, Teague JE, Schlapbach C, et al. Human skin is protected by four functionally and phenotypically discrete populations of resident and recirculating memory T cells. Sci Transl Med. 2015;7(279):279ra39.

22. Hombrink P, Helbig C, Backer RA, Piet B, Oja AE, Stark R, Brasser G, Jongejan A, Jonkers RE, Nota B, Basak O, Clevers HC, Moerland PD, Amsen D, van Lier RAW. Programs for the persistence, vigilance and control of human CD8(+) lung-resident memory T cells. Nat Immunol. 2016;17(12):1467-78. https:// doi.org/10.1038/ni.3589.

23. Levine MM, Ferreccio C, Abrego P, Martin OS, Ortiz E, Cryz S. Duration of efficacy of Ty21a, attenuated Salmonella typhi live oral vaccine. Vaccine. 1999;17(Suppl 2):S22-7. https://doi.org/10.1016/S0264-410X(99)00231-5.

24. Levine MM. Typhoid fever vaccines. In: Plotkin S, Orenstein WA, Offit PA, Edwards KM, editors. Plokin's Vaccines. 7th ed. Philadelphia: Elsevier; 2018. p. 1114-44. https://doi.org/10.1016/B978-0-323-35761-6.00061-4.

25. Booth JS, Goldberg E, Patil SA, Barnes RS, Greenwald BD, Sztein MB. Effect of live oral attenuated typhoid vaccine, Ty21a, on systemic and terminal ileum mucosal CD4+ T memory responses in humans. Int Immunol. 2018;31(2): 101. https://doi.org/10.1093/intimm/dxy070.

26. Booth JS, Patil SA, Goldberg E, Barnes RS, Greenwald BD, Sztein MB. Attenuated Oral typhoid vaccine Ty21a elicits Lamina Propria and intraepithelial lymphocyte tissue-resident effector memory CD8 T responses in the human terminal ileum. Front Immunol. 2019;10:424. https://doi.org/1 0.3389/fimmu.2019.00424.

27. Booth JS, Goldberg E, Patil SA, Greenwald BD, Sztein MB. Association between S. Typhi-specific memory CD4+ and CD8+ T responses in the terminal ileum mucosa and in peripheral blood elicited by the live oral typhoid vaccine Ty21a in humans. Hum Vaccin Immunother. 2019;15:1-12.

28. Booth JS, Goldberg E, Barnes RS, Greenwald BD, Sztein MB. Oral typhoid vaccine Ty21a elicits antigen-specific resident memory CD4(+) T cells in the human terminal ileum lamina propria and epithelial compartments. J Transl Med. 2020;18(1):102. https://doi.org/10.1186/s12967-020-02263-6.

29. Nickerson KP, Senger S, Zhang Y, Lima R, Patel S, Ingano L, Flavahan WA, Kumar DKV, Fraser CM, Faherty CS, Sztein MB, Fiorentino M, Fasano A. Salmonella Typhi colonization provokes extensive transcriptional changes aimed at evading host mucosal immune defense during early infection of human intestinal tissue. EBioMedicine. 2018;31:92-109. https://doi.org/10.1 016/j.ebiom.2018.04.005

30. Kantele A, Hakkinen M, Moldoveanu Z, Lu A, Savilahti E, Alvarez RD, et al. Differences in immune responses induced by oral and rectal immunizations with Salmonella typhi Ty21a: evidence for compartmentalization within the common mucosal immune system in humans. Infect Immun. 1998;66(12): 5630-5. https://doi.org/10.1128/IAl.66.12.5630-5635.1998.

31. Vasson MP, Farges MC, Goncalves-Mendes N, Talvas J, Ribalta J, Winklhofer-Roob B, Rock E, Rossary A. Does aging affect the immune status? A comparative analysis in 300 healthy volunteers from France. Austria and Spain Immun Ageing. 2013;10(1):38. https://doi.org/10.11 86/1742-4933-10-38

32. Strindhall J, Skog M, Ernerudh J, Bengner M, Lofgren S, Matussek A, et al. The inverted CD4/CD8 ratio and associated parameters in 66-year-old individuals: the Swedish HEXA immune study. Age (Dordr). 2013;35(3):98591. https://doi.org/10.1007/s11357-012-9400-3.

33. Li M, Yao D, Zeng X, Kasakovski D, Zhang Y, Chen S, Zha X, Li Y, Xu L. Age related human $T$ cell subset evolution and senescence. Immun Ageing. 2019;16(1):24. https://doi.org/10.1186/s12979-019-0165-8.

34. Lin Y, Kim J, Metter EJ, Nguyen H, Truong T, Lustig A, Ferrucci L, Weng NP. Changes in blood lymphocyte numbers with age in vivo and their association with the levels of cytokines/cytokine receptors. Immun Ageing. 2016;13(1):24. https://doi.org/10.1186/s12979-016-0079-7.

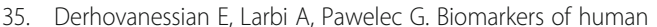
immunosenescence: impact of Cytomegalovirus infection. Curr Opin Immunol. 2009;21(4):440-5. https://doi.org/10.1016/j.coi.2009.05.012.

36. Booth JS, Patil SA, Ghazi L, Barnes R, Fraser CM, Fasano A, Greenwald BD, Sztein MB. Systemic and terminal ileum mucosal immunity elicited by Oral immunization with the Ty21a typhoid vaccine in humans. Cell Mol Gastroenterol Hepatol. 2017:4(3):419-37. https://doi.org/10.1016/j.jcmgh.201 7.08.002.

37. Darrah PA, Patel DT, De Luca PM, Lindsay RW, Davey DF, Flynn BJ, et al. Multifunctional $\mathrm{TH} 1$ cells define a correlate of vaccine-mediated protection against Leishmania major. Nat Med. 2007;13(7):843-50. https://doi.org/10.1 038/nm1592.

38. Lindenstrom T, Agger EM, Korsholm KS, Darrah PA, Aagaard C, Seder RA, et al. Tuberculosis subunit vaccination provides long-term protective immunity characterized by multifunctional CD4 memory T cells. J Immunol. 2009;182(12):8047-55. https://doi.org/10.4049/jimmunol.0801592.

39. Lin L, Finak G, Ushey K, Seshadri C, Hawn TR, Frahm N, Scriba TJ, Mahomed H, Hanekom W, Bart PA, Pantaleo G, Tomaras GD, Rerks-Ngarm S, Kaewkungwal J, Nitayaphan S, Pitisuttithum P, Michael NL, Kim JH, Robb ML, O'Connell RJ, Karasavvas N, Gilbert P, C de Rosa S, McElrath MJ, Gottardo R. COMPASS identifies T-cell subsets correlated with clinical outcomes. Nat Biotechnol. 2015;33(6):610-6. https://doi.org/10.1038/nbt.3187.

40. Fresnay S, McArthur MA, Magder L, Darton TC, Jones C, Waddington CS, et al. Salmonella Typhi-specific multifunctional CD8+ T cells play a dominant role in protection from typhoid fever in humans. J Transl Med. 2016;14(1):62. https://doi.org/10.1186/s12967-016-0819-7.

41. Fresnay S, McArthur MA, Magder LS, Darton TC, Jones C, Waddington CS, et al. Importance of Salmonella Typhi-responsive CD8+ T cell immunity in a human typhoid fever challenge model. Front Immunol. 2017;8:208. 
42. Burel JG, Apte SH, Groves PL, McCarthy JS, Doolan DL. Polyfunctional and IFN-gamma monofunctional human CD4(+) T cell populations are molecularly distinct. JCI Insight. 2017;2(3):e87499. https://doi.org/10.1172/jci. insight.87499.

43. Oja AE, Piet B, Helbig C, Stark R, van der Zwan D, Blaauwgeers $H$, Remmerswaal EBM, Amsen D, Jonkers RE, Moerland PD, Nolte MA, van Lier RAW, Hombrink P. Trigger-happy resident memory CD4(+) T cells inhabit the human lungs. Mucosal Immunol. 2018;11(3):654-67. https://doi.org/10.1 038/mi.2017.94.

44. Park CO, Fu X, Jiang X, Pan Y, Teague JE, Collins N, Tian T, O'Malley JT, Emerson RO, Kim JH, Jung Y, Watanabe R, Fuhlbrigge RC, Carbone FR, Gebhardt T, Clark RA, Lin CP, Kupper TS. Staged development of long-lived T-cell receptor alphabeta $\mathrm{TH} 17$ resident memory T-cell population to Candida albicans after skin infection. J Allergy Clin Immunol. 2018;142(2): 647-62. https://doi.org/10.1016/j.jaci.2017.09.042.

45. Goronzy JJ, Weyand CM. Successful and maladaptive T cell aging. Immunity. 2017;46(3):364-78. https://doi.org/10.1016/j.immuni.2017.03.010.

46. Haynes L, Eaton SM, Burns EM, Randall TD, Swain SL. CD4 T cell memory derived from young naive cells functions well into old age, but memory generated from aged naive cells functions poorly. Proc Natl Acad Sci U S A. 2003;100(25):15053-8. https://doi.org/10.1073/pnas.2433717100.

47. Haynes L, Maue AC. Effects of aging on T cell function. Curr Opin Immunol. 2009;21(4):414-7. https://doi.org/10.1016/j.coi.2009.05.009.

48. Effros RB, Cai Z, Linton PJ. CD8 T cells and aging. Crit Rev Immunol. 2003; 23(1-2):45-64. https://doi.org/10.1615/CritRevImmunol.v23.i12.30.

49. Koch S, Solana R, Dela Rosa O, Pawelec G. Human cytomegalovirus infection and T cell immunosenescence: a mini review. Mech Ageing Dev. 2006; 127(6):538-43. https://doi.org/10.1016/j.mad.2006.01.011.

50. Tu W, Rao S. Mechanisms underlying T cell Immunosenescence: aging and Cytomegalovirus infection. Front Microbiol. 2016;7:2111.

51. Muruganandah V, Sathkumara HD, Navarro S, Kupz A. A systematic review: the role of resident memory $T$ cells in infectious diseases and their relevance for vaccine development. Front Immunol. 2018;9:1574. https://doi. org/10.3389/fimmu.2018.01574.

52. Shin H, Iwasaki A. Tissue-resident memory T cells. Immunol Rev. 2013;255(1): 165-81. https://doi.org/10.1111/imr.12087.

53. Schenkel JM, Masopust D. Tissue-resident memory T cells. Immunity. 2014; 41(6):886-97. https://doi.org/10.1016/j.immuni.2014.12.007.

54. Douek DC, McFarland RD, Keiser PH, Gage EA, Massey JM, Haynes BF, et al. Changes in thymic function with age and during the treatment of HIV infection. Nature. 1998;396(6712):690-5. https://doi.org/10.1038/25374.

55. Dock J, Ramirez CM, Hultin L, Hausner MA, Hultin P, Elliott J, Yang OO, Anton PA, Jamieson BD, Effros RB. Distinct aging profiles of CD8+ T cells in blood versus gastrointestinal mucosal compartments. PLoS One. 2017;12(8): e0182498. https://doi.org/10.1371/journal.pone.0182498.

56. Sansoni P, Vescovini R, Fagnoni F, Biasini C, Zanni F, Zanlari L, Telera A Lucchini G, Passeri G, Monti D, Franceschi C, Passeri M. The immune system in extreme longevity. Exp Gerontol. 2008;43(2):61-5. https://doi.org/10.1016/ j.exger.2007.06.008.

57. van den Berg SPH, Wong A, Hendriks M, Jacobi RHJ, van Baarle D, van Beek J. Negative effect of age, but not of latent Cytomegalovirus infection on the antibody response to a novel influenza vaccine strain in healthy adults. Front Immunol. 2018:9:82. https://doi.org/10.3389/fimmu.2018.00082.

58. Roukens AH, Soonawala D, Joosten SA, de Visser AW, Jiang X, Dirksen K, de Gruijter M, van Dissel JT, Bredenbeek PJ, Visser LG. Elderly subjects have a delayed antibody response and prolonged viraemia following yellow fever vaccination: a prospective controlled cohort study. PLoS One. 2011;6(12): e27753. https://doi.org/10.1371/journal.pone.0027753.

59. Djennad A, Ramsay ME, Pebody R, Fry NK, Sheppard C, Ladhani SN, Andrews NJ. Effectiveness of 23-Valent polysaccharide pneumococcal vaccine and changes in invasive pneumococcal disease incidence from 2000 to 2017 in those aged 65 and over in England and Wales. EClinicalMedicine. 2018;6:42-50. https://doi.org/10.1016/j.eclinm.2018.12.007.

60. Chelimo K, Embury PB, Sumba PO, Vulule J, Ofulla AV, Long C, et al. Agerelated differences in naturally acquired $T$ cell memory to plasmodium falciparum merozoite surface protein 1. PLoS One. 2011;6(9):e24852. https:// doi.org/10.1371/journal.pone.0024852.

61. Schulz AR, Malzer JN, Domingo C, Jurchott K, Grutzkau A, Babel N, et al. Low Thymic activity and dendritic cell numbers are associated with the immune response to primary viral infection in elderly humans. J Immunol. 2015;195(10):4699-711. https://doi.org/10.4049/jimmunol.1500598.
62. McElhaney JE, Xie D, Hager WD, Barry MB, Wang Y, Kleppinger A, et al. T cell responses are better correlates of vaccine protection in the elderly. J Immunol. 2006;176(10):6333-9. https://doi.org/10.4049/jimmunol.176.10. 6333

63. Senda T, Dogra P, Granot T, Furuhashi K, Snyder ME, Carpenter DJ, Szabo PA, Thapa P, Miron M, Farber DL. Microanatomical dissection of human intestinal T-cell immunity reveals site-specific changes in gut-associated lymphoid tissues over life. Mucosal Immunol. 2019;12(2):378-89. https://doi. org/10.1038/s41385-018-0110-8.

64. Nguyen TH, McAuley JL, Kim Y, Zheng MZ, Gherardin NA, Godfrey DI, Purcell DF, Sullivan LC, Westall GP, Reading PC, Kedzierska K, Wakim LM. Influenza, but not SARS-CoV-2, infection induces a rapid interferon response that wanes with age and diminished tissue-resident memory CD8(+) T cells. Clin Transl Immunology. 2021;10(1):e1242. https://doi.org/10.1002/cti2.1242.

65. Oh SJ, Lee JK, Shin OS. Aging and the immune system: the impact of Immunosenescence on viral infection. Immunity Vaccine Immunogenicity Immune Netw. 2019;19(6):e37. https://doi.org/10.4110/in.2019.19.e37.

66. Ciabattini A, Nardini C, Santoro F, Garagnani P, Franceschi C, Medaglini D. Vaccination in the elderly: the challenge of immune changes with aging. Semin Immunol. 2018;40:83-94. https://doi.org/10.1016/j.smim.2018.10.010

67. Jackson SE, Sedikides GX, Okecha G, Poole EL, Sinclair JH, Wills MR. Latent Cytomegalovirus (CMV) infection does not detrimentally Alter T cell responses in the healthy old, But Increased Latent CMV Carriage Is Related to Expanded CMV-Specific T Cells. Front Immunol. 2017:8:733.

68. Staras SA, Dollard SC, Radford KW, Flanders WD, Pass RF, Cannon MJ. Seroprevalence of cytomegalovirus infection in the United States, 19881994. Clin Infect Dis. 2006;43(9):1143-51. https://doi.org/10.1086/508173.

69. Pawelec G, McElhaney JE, Aiello AE, Derhovanessian E. The impact of CMV infection on survival in older humans. Curr Opin Immunol. 2012;24(4):50711. https://doi.org/10.1016/j.coi.2012.04.002.

70. Wikby A, Johansson B, Olsson J, Lofgren S, Nilsson BO, Ferguson F. Expansions of peripheral blood CD8 T-lymphocyte subpopulations and an association with cytomegalovirus seropositivity in the elderly: the Swedish NONA immune study. Exp Gerontol. 2002;37(2-3):445-53. https://doi.org/1 0.1016/S0531-5565(01)00212-1.

71. Derhovanessian E, Maier AB, Hahnel K, McElhaney JE, Slagboom EP, Pawelec G. Latent infection with cytomegalovirus is associated with poor memory CD4 responses to influenza a core proteins in the elderly. J Immunol. 2014; 193(7):3624-31. https://doi.org/10.4049/jimmunol.1303361.

72. Ferreccio C, Levine MM, Rodriguez H, Contreras R. Comparative efficacy of two, three, or four doses of TY21a live oral typhoid vaccine in entericcoated capsules: a field trial in an endemic area. J Infect Dis. 1989;159(4): 766-9. https://doi.org/10.1093/infdis/159.4.766.

73. Sztein MB, Tanner MK, Polotsky Y, Orenstein JM, Levine MM. Cytotoxic T lymphocytes after oral immunization with attenuated vaccine strains of Salmonella typhi in humans. J Immunol. 1995:155(8):3987-93.

74. Booth JS, Toapanta FR, Salerno-Goncalves R, Patil S, Kader HA, Safta AM, et al. Characterization and functional properties of gastric tissue-resident memory $T$ cells from children, adults, and the elderly. Front Immunol. 2014:5:294.

75. Booth JS, Salerno-Goncalves R, Blanchard TG, Patil SA, Kader HA, Safta AM, et al. Mucosal-associated invariant T cells in the human gastric mucosa and blood: role in helicobacter pylori infection. Front Immunol. 2015;6:466.

76. Eiras P, Roldan E, Camarero C, Olivares F, Bootello A, Roy G. Flow cytometry description of a novel CD3-/CD7+ intraepithelial lymphocyte subset in human duodenal biopsies: potential diagnostic value in coeliac disease. Cytometry. 1998;34(2):95-102. https://doi.org/10.1002/(SICI)1097-0320(1 9980415)34:2<95::AID-CYTO6>3.0.CO;2-B.

77. Salerno-Goncalves R, Fernandez-Vina M, Lewinsohn DM, Sztein MB. Identification of a human HLA-E-restricted CD8+ T cell subset in volunteers immunized with Salmonella enterica serovar Typhi strain Ty21a typhoid vaccine. J Immunol. 2004;173(9):5852-62. https://doi.org/10.4049/jimmunol.1 73.9.5852

\section{Publisher's Note}

Springer Nature remains neutral with regard to jurisdictional claims in published maps and institutional affiliations. 